\title{
Feminismos jurídicos y pluriculturalidad: Ensayando una visión en tiempo de pandemia
}

\author{
Legal feminisms and multiculturalism: \\ Rebearsing a vision in times of pandemic
}

\author{
Erika Silvina Bauger ${ }^{1}$ \\ Universidad Nacional de La Plata - Argentina
}

Revista Derechos en Acción ISSN 2525-1678/ e-ISSN 2525-1686

Año 5/N 16 Invierno 2020 (21 junio a 20 septiembre), 625-677

DOl: https://doi.org/10.24215/25251678e437

Recibido: 01/07/2020

Aprobado: 15/09/2020

\section{Introducción}

Antes de introducirnos en el tema ${ }^{2}$, conviene traer aquí el pensamiento de Foucault interpretado por Femenías (2000), en

\footnotetext{
1 Abogada, egresada con Diploma de Honor y Medalla de la UNLP. Premio "Joaquín V. González". Auxiliar Docente con funciones de Adjunta de la Cátedra I de Derecho Internacional Privado de la FCJyS. de la UNLP. Miembro del Instituto de Derecho Internacional Privado del CALP, AADI y ASADIP. Especialización en Derecho Internacional Privado Universidad de Salamanca. Becaria de investigación en Iniciación, Perfeccionamiento y Formación Superior de SECyT de la UNLP. Maestranda en Relaciones Internacionales y en Derechos Humanos de la UNLP. Estudiante de la Especialización en Docencia Universitaria de la UNLP. Coordinadora y docente del Seminario "Género y Derecho" de la Red de Profesoras de la FCJyS e integrante del Observatorio de Enseñanza del Derecho de la UNLP. ebauger@gmail.com ebauger@jursoc.unlp.edu.ar. (ORCID: https://orcid.org/0000-0002-6207-4203).

2 El tema en análisis "Feminismos jurídicos y Pluriculturalidad", lo doy en una de las clases del Seminario "Género y Derecho" de la Red de Profesoras de la FCJyS de la UNLP. El Seminario propone analizar, desde una perspectiva crítica, el papel desempeñado por el Derecho en la estructuración y el mantenimiento del patriarcado y el androcentrismo epistémico, para luego confrontarlo con una perspectiva de género de los derechos. Las primeras clases tratan la conformación de un sistema jurídico excluyente de las mujeres otras disidencias y luego,
} 
torno a desarmar el argumento de la "legitimación epocal" o contextualista. Cada época determina límites de decibilidad y visibilidad. Hay enunciados que no circulan en ciertos momentos porque no hay condiciones para inteligirlos. Cada época, cada cultura establece códigos (implícitos) que rigen los esquemas perceptivos, el lenguaje, los valores y las prácticas. Pero en el caso de la opresión de las mujeres y otras identidades no hegemónicas hay una suerte de continuum histórico. Cuestiones como el binarismo, la dicotomización de lo humano en dos categorías mutuamente excluyentes, la construcción de cadenas semánticas asociadas de modo binario y la jerarquización de las categorías binarias, son un a priori histórico patriarcal. Siguiendo a Foucault (1966: 5) "Nada hay más vacilante, nada más empírico (cuando menos en apariencia) que la instauración de un orden de cosas". ${ }^{3}$ Por esto y para revisar estas cuestiones fundantes y las trampas del "género" que muestran como "natural" aquello que es culturalmente construido y sobre las que se erigen todas las exclusiones y violencias contra las mujeres y

abordar diversas instituciones jurídicas desde un derecho emancipador y antidiscriminatorio. Entendemos la perspectiva de género como "una voluntad política por transformar el orden de géneros. Se reconoce no sólo que existe un orden de géneros, sino que además se le considera opresivo. Colocarse en la perspectiva de género implica no sólo reconocer que hay un orden social que nos divide como hombres y mujeres, que niega las mínimas igualdades democráticas a medio mundo, sino que también implica anunciar públicamente que una está en una posición contraria a la opresión de género, y cuando somos más radicales, estamos además a favor de intervenir con una voluntad activa en la construcción de alternativas no opresivas de género (Lagarde, 1996, s/d).

El Seminario atraviesa el plan de estudios de la carrera de abogacía a partir de análisis feministas de derecho, abordando los temas a partir de voces plurales compuestas por docentes de la carrera de diversas materias, que forman parte de la Red de Profesoras de la Facultad de FCJyS.

A lo largo del seminario, se estudian las herramientas tanto teóricas como prácticas, que desde las propuestas feministas y emancipadoras han puesto al Derecho al servicio de la conformación de una nueva ciudadanía, igualitaria, plural y participativa.

3 En Las palabras y las cosas, Foucault define "a priori histórico": "Es lo que, en una época dada, recorta un campo posible del saber dentro de la experiencia, define el modo de ser de los objetos que aparecen en él, otorga poder teórico a la mirada cotidiana y define las condiciones en las que puede sustentarse un discurso, reconocido como verdadero, sobre las cosas" (Foucault, 1966: 158) 
otras identidades no hegemónicas, revisar, recuperar y construir genealogías para nuestras luchas, resulta -para mí- fundamental.

Como sostiene Butler (1999) para las feministas que entendemos no poder prescindir de un marco normativo para mostrar la irracionalización del sistema de género-sexo (sistema que, si no se irracionaliza ni siquiera se ve: sólo se manifiesta como lo que es, como un sistema de dominación, a la mirada crítica y extrañada), pienso que todo depende del uso que se haga de la "caja de herramientas", en que nuestro/a autor/a, modestamente, hace consistir sus aportaciones teóricas. El oprimido no puede crear desde cero un lenguaje alternativo, un discurso absolutamente otro, en el que dar forma a su experiencia: su recurso consiste en resignificar su "caja de herramientas" con una intención política.

En líneas generales, por cada discurso o tratado sosteniendo una posición de exclusión, existió una (o)posición que defendió lo contrario. El problema como decía Benjamin es quién escribe la historia y qué discursos y relatos nos llegan. Así: “...no cualquier presente puede conectarse con cualquier pasado, sino solamente con aquellos que conforman su singular genealogía o árbol de raíces específicas, también debe de ser claro que el pasado no posee nunca una "imagen 'eterna'" y ya acabada, sino que es siempre algo vivo y abierto, algo cuyos sentidos últimos no terminan de revelarse...." (Benjamin, 2002: 55)

En esta línea de pensamiento y como plataforma política, me parece interesante recuperar algunos debates teóricos respecto al pensamiento de los filósofos griegos en la antigüedad clásica, en torno a las ideas y heterodesignaciones respecto del lugar que debían ocupar las mujeres. Obviamente, esto es un recorte grosero de la historia que traigo sólo como ejemplo del uso de la "caja de herramientas" y que merece un estudio más acabado que no es motivo de este ensayo.

Me interesa trae aquí el antecedente de educación igualitaria que propone Platón en el siglo IV a.c. donde presenta una teoría política patriarcal pero más igualitarista que la que luego 
desarrollará Aristóteles. ${ }^{4}$ Siguiendo a Santa Cruz (1999), en la República, Platón presenta por primera vez de modo orgánico una teoría de justicia que constituye una concepción ideal del Estado. En el libro V ofrece una propuesta sobre las mujeres y las familias. La autora identifica tres "olas" de oposición de creciente intensidad que debe sortear Sócrates: 1. la admisión de las mujeres como guardianas; 2 . la comunidad de mujeres y de hijos: 3. la practibilidad del Estado ideal.

Platón introduce una concepción que hace consistir a la justicia en el ejercicio de la función propia, trátese del individuo o del Estado. La justicia en la polis consiste en que "cada uno debe atender a una sola de las cosas de la ciudad: a aquello para lo que su naturaleza está mejor dotada" (433a). "Hacer cada uno lo suyo y no multiplicar las actividades, eso es la justicia" (433b). La justicia requiere, pues, que cada uno se dedique, ante todo, a una única actividad y que no pretenda desplegar múltiples tareas, y, en segundo lugar, que esa única actividad sea aquella para la cual su naturaleza lo capacita. La novedad que Platón introduce es, pues, la del hacer cada uno lo suyo, frente al dar o recibir lo que a cada cual corresponde. Sin embargo, el hacer lo propio no excluye, sino que engloba el tener lo que a cada cual le corresponde; y Platón lo dice explícitamente: "tanto la posesión como la práctica de lo que a cada uno es propio será reconocida como justicia" (433e-434a). (Santa Cruz, 1999: 87).

Siguiendo el análisis de Santa Cruz (1999), al comienzo del libro V, Platón hace frente a la primera "ola" de oposición y dedica unas cuantas páginas a justificar la admisión de las mujeres en la clase de los guardianes, y la consecuente necesidad de impartir a hombres y mujeres una educación igualitaria. Parte

\footnotetext{
4 A la vez, estaban también los sofistas, que en la misma época denunciaban la esclavitud y la supuesta inferioridad de las mujeres. Lo mismo respecto de la defensa de la "esclavitud natural" que Aristóteles hace en la Política, donde el propio Aristóteles se refiere a "otros (creen) que la dominación es contra naturalize, pues el esclavo y el libre lo son por convención, pero en nada difieren por su naturalize" (Política, 1253 b 4)
} 
de la metáfora de los perros guardianes: las hembras deben cumplir las mismas tareas que los machos, y no quedarse en sus casas, imposibilitadas por los partos y por la crianza de los cachorros; pero, para poder cumplir las mismas tareas, con la sola diferencia de que las hembras son más débiles, es preciso darles el mismo adiestramiento. "Así también, si las mujeres de los guardianes han de cumplir las mismas tareas que los varones, también ellas, análogamente, deben recibir las mismas enseñanzas -música, gimnasia y todo lo relativo a la guerra- y ser tratadas de la misma manera...", (451d a 452d). El punto de partida es claro: si ha de asignarse a mujeres y hombres las mismas tareas, habrá que impartirles la misma educación.

Prima facie, en el ideal de justicia de Platón no existía una diferencia "de naturaleza" (eide) entre varones y mujeres. Para Platón, no existen funciones propias de las mujeres, sino que la virtud y la función son características de cada individuo. Ergo, las mujeres podrían ejercer iguales funciones pudiendo gobernar y participar en la política. Para Aristóteles, en cambio "en la relación entre macho y hembra, por naturaleza, uno es superior y otro inferior, uno manda y otro obedece" (Política, 1254 b7). La educación de las mujeres se subordina, pues, a los objetivos de la polis organicista, de modo que su virtud, como ya demostraremos (supra) depende de la filiación con la estructura social que la determina. La ontología aristotélica y su teoría de la justicia están diseñadas para justificar las exclusiones políticas que de hecho tenían lugar en la época (Femenías, 1988). Estaríamos ante lo llamado por Hume "falacia naturalista" que consiste en inferir el "deber ser" del "ser".

\footnotetext{
5 A diferencia de Platón, Aristóteles ni siquiera plantea la posibilidad de que las mujeres puedan tener algún tipo de participación política. La mujer "naturalmente" es inferior al varón y su función específica consiste en obedecer y someterse a la autoridad del oikosdespotés. En Política (ca. 344 a.c.) se aleja del modelo platónico de polis como "gran familia". Separa por un lado, la familia (extensa) donde rigen los afectos, el oikos, lo privado, el varón (padre) y sus propiedades, los hijes, esposa y esclavos en una grada inferior, y una "monarquía" (donde manda uno). Por otra lado se encuentra el Estado (politeia) donde rigen la ley, la polis, lo público, el ciudadano (varones propietarios) y la "república" (hombres libres e iguales).
} 
Este antecedente de educación igualitaria entre varones y mujeres, recibió un análisis en cuanto a las limitaciones del enfoque marcadas por Moller Okin, que sostiene que Platón en un primer momento cuestiona las costumbres de su época y logra, aunque sólo sea para la clase de los guardianes, colocar a la mujer en un lugar homólogo al de los varones. Sin embargo, aquella libertad que plantea en La República entra en contradicción con las regulaciones particulares estipuladas en Las Leyes, cuando reinstaura la categoría de "familia". "Así, el valor de sus cuestionamientos al orden establecido queda relegado a intenciones, sin que veamos la posibilidad de aplicación práctica" (Moller Okin, 1989:45-46).

Compartimos con Piccone el siguiente razonamiento: "Más allá de la mentada debilidad de las mujeres, la afirmación es extraordinaria: hombres y mujeres poseen la misma naturaleza y, por ende, las mismas aptitudes para todas las ocupaciones, dudamos de qué siquiera en la actualidad este sea un pensamiento mayoritario" (Piccone, 2018: 140).

No obstante estas críticas, me parece valioso y no sólo placer erudito recuperar estos debates conceptuales respecto a los filósofos griegos y reconstruir la historia con una intencionalidad. En concreto, la reconstrucción teórica nos permite visibilizar los límites de las teorías que han pasado el canon y cómo se fueron construyendo estas antinomias que colocan a las mujeres, hijes, y otras identidades no hegemónicas en un lugar de subordinación. Construir genealogías nos sirven como plataforma de acción para una variedad de trabajos en nuestra Facultad de Ciencias Jurídicas y Sociales de la UNLP, pero deconstruidas a la luz de estos desarrollos.

En suma y siguiendo a Olsen (1990):

Desde el surgimiento del pensamiento liberal clásico, y tal vez desde los tiempos de Platón, nuestro pensamiento se ha estructurado en torno de series complejas de dualismos o pares opuestos: racional/irracional, activo/pasivo, pensamiento/sentimiento, razón/emoción, cultura/naturaleza, poder/sensibilidad, objetivo/subjetivo, abstracto/ 
concreto, universal/particular. Estos pares duales dividen las cosas en esferas contrastantes o polos opuestos. Tres características de este sistema de dualismos resultan importantes para la discusión que sigue. Primero, los dualismos están sexualizados. Una mitad de cada dualismo se considera masculina y la otra mitad, femenina. En cada par, el término identificado como "masculino" es privilegiado como superior, mientras que el otro es considerado como negativo, corrupto o inferior. $\mathrm{Y}$ tercero, el derecho se identifica con el lado "masculino" de los dualismos. (Olsen, 1990:1).

Siguiendo estos lineamientos, cabe hacernos algunas preguntas que funcionarán como disparadores: ¿cuándo surge el movimiento feminista? ¿Qué características tiene? ¿Son valiosas las genealogías del feminismo elaboradas desde los países centrales para comprender este movimiento social? ¿Existe un feminismo o distintos tipos de feminismos jurídicos?

Siguiendo a Freedman (2004), compartimos que el feminismo o los feminismos constituyen una praxis emancipadora de las mujeres y las personas disidentes de la heteronormatividad. La autora sostiene que no se puede hablar de feminismo en un sentido unitario y que resulta pretensioso esperar responder en forma unívoca la pregunta respecto de ¿qué es el feminismo? El vocablo encierra una pluralidad de sentidos en los que identificamos sustratos comunes: la vocación por develar la subordinación a la que hemos sido sometidas históricamente las mujeres, la discriminación que sufrimos a partir de nuestra condición y la lucha por construir sociedades y sistemas políticos que logren erradicar estas discriminaciones (Freedman, 2004: 16).

Dentro de su heterogeneidad, muchas autoras utilizan el término "olas", como metáfora para señalar los hitos en la evolución de los movimientos feministas. Así, el hilo conductor de cada etapa propuesta la constituyen las reivindicaciones y demandas de inclusión ciudadana y de acceso a derechos de las mujeres y las herramientas conceptuales y analíticas que éstas han elaborado para evidenciar las exclusiones y fundamentar sus 
derechos. No obstante, y como más adelante veremos, desde una epistemología decolonial o subalterna se han cuestionado estas "olas", sosteniendo que existe un activismo fuera de las mismas. La periodización entonces, no será universal sino contextualizada en Europa y Estados Unidos y en los tiempos de esos espacios, y no debemos trasladarla automáticamente a Latinoamérica y a Argentina. Es decir, es imposible pensar en crear una única línea de tiempo, una historia del feminismo universal, ya que por ejemplo, en América Latina y en nuestro país, la década del setenta -y que en apariencia correspondería a la "segunda ola" del feminismo-, se vio limitada por las dictaduras militares.

Efectuada esta advertencia y siguiendo a Costa Wegsman (2011), los feminismos jurídicos se pueden situar históricamente en la década de los setenta en los Estados Unidos como articulación de los activismos feministas y en sus diversas manifestaciones teóricas: liberales, marxistas, radicales, poscoloniales, postmodernas, entre otras, que generaron distintas estrategias de acción. Asimismo, originaron heterogéneas recepciones en los campos disciplinares como la filosofía, la sociología y la política, conectados también a problemas en torno a casos judiciales y atravesando agendas políticas diferentes según el contexto institucional. Es decir, no podemos hablar de un sólo tipo de feminismo jurídico sino de varios que plantean perspectivas de trabajo situadas en los distintos contextos y ancladas en necesidades específicas de las mujeres y otras identidades no hegemónicas LGTBIQ (Lesbianas, Gays, Trans, Bisexuales, Intersexuales, Queer) ${ }^{6}$.

Durante el Siglo XX emerge una amplia tradición que comprende al Derecho no sólo en su función social sino también

6 En los noventa crearon un movimiento apropiándose de la palabra" queer" y convirtiéndola en aquella que identificara un nuevo movimiento en el que el sexo y el género estuvieran en eterna construcción y transformación. Estas personas sintieron que muchos gays y lesbianas querían imitar el modelo de familia heterosexual estadounidense. "El término será cuestionado, remodelado y considerado obsoleto en la medida en que no ceda a las demandas que se oponen a él precisamente a causa de las exclusiones que lo movilizan", sostiene Judith Butler, una de las madres de este movimiento, en su ensayo "Acerca del término queer". 
como un fenómeno social. Los feminismos jurídicos pueden ubicarse en esta tradición, aunque, previamente a la conformación del campo, los feminismos en sus múltiples expresiones anticiparon dicho enfoque crítico. Se trata de una particular comprensión del Derecho y las estructuras jurídicas modernas, que genera a su vez nuevas claves de lectura de la normativa legal. La comprensión del Derecho como un fenómeno que excede la pura normativa jurídica y se encuentra indisolublemente asociado a lo social, lo cultural y lo político, se advierte en los desarrollos teóricos elaborados por mujeres a partir de la modernidad. El panorama abierto no siguió una única lógica ya que aparecieron múltiples ramas que se combinaron, entremezclaron, mantuvieron fieles a sus orígenes o los contrariaron y criticaron radicalmente (Costa Wegsman, 2011).

\section{Feminismos jurídicos. Diferentes tendencias u "olas"}

Delimitar las olas o tendencias feministas a partir de las demandas de inclusión ciudadana de las mujeres -luchas por acceder a los mismos derechos que los varones- y de las demandas de ampliación de derechos de los feminismos -conquistar y hacer efectivos esos y otros derechos a partir de claves conceptuales propias que no están presentes en leyes e instituciones tradicionales-, nos permite esclarecer las cuestiones centrales de cada período. Estos procesos y estas demandas, adquieren características particulares y tiempos propios en diversos contextos y culturas, manifestándose a ritmos desiguales.

Por eso, efectuaré un breve recorrido sobre las diferentes "olas", como una manera de reunir el pensamiento feminista en grandes etapas y destacar dentro de la heterogeneidad de los movimientos, epicentros conceptuales y reivindicaciones que describen una época. Estas etapas u "olas" están interconectadas entre sí.

Siguiendo a Biswas:

Referirnos a olas implica considerar las diferentes tendencias y ramas de un mismo movimiento. Lo que caracteriza 
a una y a otra son usualmente diferencias de opinión o interpretación de una idea. De cualquier manera, todas las olas deben de mantener ciertos preceptos. En el caso de las feministas, aunque algunas sean seguidoras de la segunda y otras se inclinen más por la tercera ola, todas -y todos- luchan por dar poder a las mujeres y conseguir una posición social igual a la de los hombres y por lograr la participación femenina en la toma de decisiones, sean éstas en el ámbito público o privado. (Biswas, 2004: 70)

La primera ola del feminismo suele ubicar sus gérmenes en el pensamiento ilustrado de las mujeres del siglo de las luces y se extiende hacia el final de los años cuarenta del siglo XX, cuando las mujeres de la mayoría de los países occidentales ya contaban con el derecho a votar. ${ }^{7}$ Así nos encontramos con la demanda de incorporación a la ciudadanía y al sufragio en la primera ola. ${ }^{8}$ Partimos, entonces, de la noción "moderna" de sujeto y de las críticas al contractualismo para, luego de examinar las Declaraciones de Derechos vinculadas a la Ilustración, pasar a revisar las críticas más importantes a los modelos liberales y marxista. Un punto de partida será la obra crítica de Simone de Beauvoir y sus seguidoras.

7 En Argentina, la lucha de las mujeres por obtener el sufragio y por participar en los espacios de decisión política fue y sigue siendo ardua. La ley de sufragio se promulgó en 1947 (Giddens, 1999: 450). Sólo en Nueva Zelanda el sufragio se conquistó en el siglo XIX (1893). En los primeros años del siglo XX se logró el acceso al voto en Australia y los países de la península escandinava. En el marco de la Revolución Rusa (en lo que llegaría a ser la Unión de Repúblicas Socialistas Soviéticas), fue aprobado en 1917. Finalizada la Gran Guerra, llegó el turno de Austria, Alemania, Holanda, Polonia, Suecia, Luxemburgo y Checoslovaquia entre otros países. Por la misma época en Estados Unidos (1920) y bastante después Gran Bretaña (1928). Ecuador es pionero en Latinoamérica (1929) seguido de Brasil y Cuba en 1934. Otros países europeos reconocieron el derecho al sufragio femenino a partir del final de la Segunda Guerra Mundial: Francia, Hungría, Italia, Japón, Yugoslavia y Bolivia.

8 Recomiendo ver el documental: Sufragistas. Pioneras de las luchas feministas - Canal Encuentro, que muestra las luchas por la participación política y en la vida social que llevaron a cabo exponents argentinas de la primera ola: Julieta Lanteri, Cecilia Grierson, Elvira Rawson, Alicia Moreau de Justo, Carolina Muzzilli, Virginia Bolten, Salvadora Medina Onrubia, Alfonsina Storni, Enriqueta Lucero, entre otras. Disponibles en: https://www.youtube.com/ watch?v=9Bwcemo-cjY\&t=210s. https://www.youtube.com/watch?v=1hJFFiKGCy8. https:// www.youtube.com/watch?v=UMTIhc5Jb70. 
Una segunda ola, aspira a la participación en los campos de toma de decisión por parte de las mujeres, así como también, un control más amplio sobre algunos asuntos privados como la igualdad sexual y el aborto. Se acuña el concepto de patriarcado y la ruptura de la frontera entre el espacio público y privado que forma parte de la concepción política feminista en la segunda ola.

La tercera ola, es la que pretende conseguir "un enfoque más perspicaz en los asuntos concernientes a las zozobras femeninas por medio del estudio de las particularidades de cada grupo y la exaltación de la diversidad cultural, social, religiosa, racial y sexual" (Biswas, 2004: 66). Aquí se requiere el abordaje de las diferencias entre las femineidades a partir de la década de los ochenta. Se comienza a problematizar no sólo las marcas de la "diferencia sexual" en vinculación con las "políticas de la identidad", sino también otras diferencias como los entrecruzamientos de etnorazas o de religiones (Femenías, 2000). Nos interesa mostrar cómo el problema de "la identidad" desemboca en un conjunto complejo de intersecciones que, al menos, obliga a replantear nuevamente la cuestión del "sujeto" (incluido el "sujeto" de derecho) y, consecuentemente, de los modos de plantear el conjunto de reclamos y limitaciones vinculados. Aquí se va a discutir la compleja categoría de género y la pluralidad de sujetos del feminismo que caracterizan a la tercera ola y el concepto de interseccionalidad.

En la era de las redes sociales, el ciberfeminismo, la viralidad y los "hashtags", el movimiento feminista no ha esperado a las historiadoras para proclamar que estamos viviendo una cuarta ola. Llegó cuando logró el objetivo de desbordar las convocatorias de huelgas en los 8 de marzo de 2018, 2019 y 2020. La cuarta ola -considerada como continuación histórica de las olas precedentes-, se perfila en la actualidad como un movimiento de carácter internacional de reacción unánime frente a la violencia patriarcal, incluyendo el feminicidio y la falta de reconocimiento de los Derechos Humanos de las mujeres y otras disidencias en los diversos ámbitos en las sociedades 
a nivel mundial. Su manifestación reivindicativa es a través de convocatorias a nivel nacional e internacional con importantes manifestaciones en las calles. La periodista argentina Florencia Alcaraz, del colectivo \#Ni Una Menos, iniciado en 2015 y que logró convocar una manifestación masiva en Buenos Aires contra los feminicidios, señala la vinculación del feminismo a los movimientos sociales en esta ola. Afirma que "Es un feminismo popular, que se construye de abajo hacia arriba, que tiene un componente muy vinculado a los movimientos sociales y que habilita a muchas más a ser feministas" (...) "Se corrieron los márgenes y los límites y el feminismo logró llegar a muchísimas más mujeres" (Alcaraz, 2017)

Esta ola no sólo se articula en las calles sino también a través de la creación de contenidos audiovisuales y escritos de carácter filosófico, político, económico, social, ecológico y cultural -académicos o no-, y de la difusión de los mismos a través de las redes sociales y los medios de comunicación tradicionales. ${ }^{9}$

Como colofón a esta primera parte, podemos señalar que los aportes de las distintas olas feministas se encuentran interrelacionados entre sí y hoy asistimos al reclamo del avance en la agenda inconclusa de la paridad y la defensa de los derechos de las mujeres como Derechos Humanos. En otras palabras, la traducción moral y jurídica del universalismo interactivo tiene como terreno privilegiado, el ámbito de los Derechos Humanos, y ello no es producto del azar. Diversas variables intervinientes inciden en tal realidad. Entre las mismas corresponde destacar muy especialmente el desarrollo de los medios de comunicación internacional -que permiten volúmenes cada vez más

9 Rosa Cobo sostiene que esta ola se erige para enfrentar el desarrollo de un neoliberalismo caracterizado por frenar los avances legislativos y de políticas públicas encaminados a conseguir la igualdad de derechos para las mujeres (Cobo, 2015).

En suma, esta oleada se configura como una respuesta socio-política, filosófica, económica y cultural que se suma al movimiento asociativo generando espacios que invitan a reflexionar, debatir y proponer soluciones prácticas y medidas legislativas que protejan la igualdad de las mujeres, sus derechos fundamentales y ayuden a erradicar la violencia machista en todas sus manifestaciones a nivel global (Mastrodoménico, 2018). 
significativos de interacción de personas- así como la creciente flexibilización de las fronteras nacionales, consecuencia de procesos de integración e interrelación entre los Estados, no sólo a nivel regional, sino también en el ámbito global.

En concreto, en la discusión feminista transnacional, el gran debate hoy reside en la exigencia de muchas feministas del Sur de un compromiso antineoliberal de las feministas del Norte, así como que enfaticen la autocrítica cultural frente al uso sensacionalista de la situación de las mujeres en países del llamado Tercer Mundo y del mundo árabe-islámico (Guerra Palmero, 2010). Este panorama nos exige elaborar una agenda feminista global acorde con sus exigencias. Los movimientos queer ponen en cuestión fronteras entre los géneros, llevando a debate este mismo concepto; en los países que han sufrido la colonización de Occidente se genera un feminismo con modulaciones propias, el "feminismo poscolonial"; los ecofeminismos dan forma a la convergencia de ciertas perspectivas feministas y la problemática ecológica; la feminización de los "flujos migratorios" vuelve apremiante contrastar los Derechos Humanos de las mujeres con el fenómeno de la multinacionalidad (Amorós, 2005). Nuestro acceso a las tecnologías de la información y comunicación -especialmente en estos tiempos de pandemia- y lo que se ha denominado ciberfeminismo, nos involucra en alianzas con nuevos sujetos/ as emergentes y las nuevas relaciones entre capital y trabajo en la era global están implantando un nuevo orden del género. De tal forma, la teoría feminista se está cargando a sus espaldas numerosos y variados temas de reflexión y deconstrucción.

\section{II.1. Tercera ola: feminismos jurídicos de las particularidades culturales, sociales, religiosas, raciales y sexuales}

Los debates acerca de la relación entre la pluriculturalidad y los feminismos jurídicos sólo pudieron plantearse a partir de lo que se denomina la "tercera ola feminista", que aparece hacia mediados de los años ochenta y parte del cuestionamiento acerca de qué significa ser "mujer", en virtud de la pluralidad de 
mujeres en contextos fácticos, culturales, políticos y económicos diversos y enfrentadas a distintas problemáticas (Bauger, 2019).

Dentro de los feminismos jurídicos de las particularidades culturales, sociales, religiosas, raciales y sexuales, retomar la pregunta de Susan Moller Okin (1999) respecto a “¿Es el multiculturalismo malo para las mujeres?" planteada como disparador al inicio de este ensayo, se justifica para analizar las posiciones de los feminismos jurídicos argentinos en el caso "Fabián Ruiz"10. La pregunta en este marco está relacionada aquí, con el lugar que ocupan las suposiciones acerca de la identidad cultural en esta lógica universal de los Derechos Humanos y la vinculación de esa lógica identitaria con la situación subordinada de las mujeres y otras identidades contrahegemónicas ${ }^{11}$ dentro de la realidad cultural que esta lógica revela.

La unicidad de la mujer normativa no se corresponde con las diferencias y con las desigualdades entre las mujeres. La posibilidad de incorporar la perspectiva de las mujeres en el derecho se confronta con las experiencias de otras mujeres que son invisibilizadas mediante la pretendida universalidad de la mujer en la letra de la ley. Las figuras jurídicas procuran referir a un conjunto que es siempre diverso y dinámico. Mediante la figura normativa de mujer, el discurso jurídico ocluye a todas aquellas que no concuerdan con esa figura normativa (Lerussi y Costa, 2018: 10).

Nancy Fraser ${ }^{12}$ señala que en Estados Unidos los debates feministas sobre la diferencia han atravesado, a grandes rasgos,

\footnotetext{
10 CJS, “C/C Ruiz, José Fabián s/Recurso de Casación”. (Expte. N ${ }^{\circ}$ CJS 28.526/06).

11 El concepto de contrahegemonía tiene su matriz en el concepto de hegemonía desarrollado principalmente por Antonio Gramsci (1891-1937), para quién en las condiciones del estado moderno una clase mantiene su dominio no simplemente mediante una organización especial de la fuerza, sino porque es capaz de ir mas allá de sus intereses estrechos y corporativos, de ejercer un liderazgo moral e intelectual y de realizar compromisos con una variedad de aliados que se unifiquen en un bloque popular. En: Francisco Hidalgo Flor (Universidad Central del Ecuador). Diccionario de pensamiento alternativo. Disponible en: http://www.cecies.org/ articulo.asp?id=167

12 Nancy Fraser (Baltimore, 20 de mayo de 1947) es una filósofa política, intelectual pública y feminista estadounidense. Ha ejercido como profesora de ciencias políticas y sociales. En
} 
dos fases. En la primera que duró desde finales de los años sesenta hasta mediados de los ochenta aproximadamente, la atención se centraba en la "diferencia de género". En la segunda fase, que va más o menos desde mediados de los ochenta hasta el presente, el interés se ha trasladado a las "diferencias entre mujeres"13. Las principales corrientes feministas habían rechazado la idea de que la diferencia entre géneros pudiese ser provechosamente discutida si se la aislaba de los ejes de diferencia "raza", etnicidad, sexualidad y clase. Y de este modo, el debate en torno a la igualdad/diferencia sufría un desplazamiento. Se inauguraba así, una nueva ola feminista centrada en las "diferencias entre mujeres". El cambio en Estados Unidos se debió a la influencia, según la autora, de lesbianas y feministas de color, que durante muchos años habían criticado las formas de feminismo que no conseguían iluminar sus vidas ni expresar sus problemas. Las mujeres afroamericanas, por ejemplo, habían invocado su historia de esclavitud, resistencia, trabajo asalariado y activismo comunitario para oponerse a la idea

la actualidad es profesora de filosofía en The New School en Nueva York. Es ampliamente conocida por sus críticas y contribuciones teóricas en el ámbito de la filosofía política, especialmente es cuestiones de política de la identidad, sobre el constructo de justicia social y la teoría feminista.

${ }^{13}$ La tesis de Fraser consiste en reconstruir la historia de los debates feministas sobre la diferencia en Estados Unidos con el fin de mostrar cómo y dónde surgen los problemas que en la actualidad se nos plantean. Y donde ello sea posible, la autora sugiere las formas de enfrentarlos. Desarrolla las ideas centrales del feminismo de la igualdad (primera ola) y el feminismo de la diferencia (de segunda ola), hasta llegar a la década de los noventa donde el contexto estadounidense había cambiado de un modo radical de modo que las perspectivas de los feminismos anteriores debían ser planteados, en otros términos. La corriente principal del feminismo norteamericano privilegiaba el punto de vista de las mujeres blancas, anglosajonas, heterosexuales y de clase media que habían dominado el movimiento durante tanto tiempo y a partir de cuyas experiencias y condiciones de vida extraía conclusiones inapropiadas, e incluso perjudiciales, para otras mujeres. De esta manera, el mismo movimiento que pretendía liberar a las mujeres terminaba reproduciendo dentro de sus mismas filas las tendencias racistas y heterosexistas, las jerarquías de clase y los prejuicios étnicos que eran endémicos en la sociedad de Estados Unidos. Estas voces relegadas al principio a las márgenes del feminismo norteamericano, a finales de los ochenta pasaron en palabras de Bell Hooks "de (la) periferia a(l) centro" de la discusión. El movimiento feminista había estado tan preocupado por la diferencia de género que había descuidado las diferencias entre mujeres. 
de que la dependencia de la mujer respecto al hombre y su confinamiento al ámbito doméstico eran hechos universales. Mientras tanto las feministas latinas, judías, americanas nativas, y oriundas de Asia habían criticado la referencia implícita a las mujeres blancas anglosajonas en muchos textos de las principales corrientes del feminismo. Las lesbianas habían desenmascarado en muchos análisis feministas clásicos de la maternidad, la sexualidad, la identidad genérica y la reproducción referencias a una heterosexualidad elevada a norma (Fraser, 1995: 41).

Según Biswas (2004) es necesario establecer una nueva ola feminista con el propósito de responder a la situación global y a los diferentes rasgos que hacen de cada comunidad algo único y que, por lo tanto, provocan diferentes reacciones ante ciertos acontecimientos e ideologías. Esta nueva ola surge como resultado de las particularidades religiosas, culturales, educativas, políticas y fisonómicas en el interior de los movimientos feministas. "Los cambios culturales y sociales que han tenido lugar en el mundo han formado y transformado nuestra percepción de quienes somos, qué queremos y cuándo es que lo queremos (...)." (Biswas, 2004: 69). Mujeres latinoamericanas, mujeres negras y provenientes de sectores económicos desfavorecidos comenzaron a revolucionar la manera en la que podían convertirse en feministas y activistas de su propia causa. Mujeres provenientes de países pobres, de diversas clases sociales, pertenecientes a religiones, culturas y formación educativa disímiles no se precipitaron ni se precipitan a las calles demandando igualdad, porque el tipo de igualdad que estaban y están buscando es diferente a la perseguida por las feministas europeas o norteamericanas. Estas mujeres necesitan combatir primero la pobreza, la discriminación, la injusticia social y la marginación, al tiempo que puedan tener acceso a los sistemas educativos, a los sistemas de salud y de seguridad social. Estos grupos tienen que luchar contra la violencia doméstica, el abuso sexual y la mutilación de órganos genitales. "Y una vez que hayan logrado lo anterior, todas las mujeres (...) serán más libres y el feminismo, o al menos su precepto 
básico por la igualdad, se habrá convertido parcialmente en realidad" (Biswas, 2004: 69).

En esta tercera oleada, que llamamos feminismos de las particularidades, se comienza a analizar críticamente el concepto femenino, siendo que algunas teorías van más allá del término "mujer/mujeres" para considerar otras identidades "feminizadas" como las identidades "trans".

\section{II.1.1. El género en disputa: el feminismo y la subversión de la identidad ${ }^{14}$}

En esta tercera ola se puede ubicar a Judith Butler, con su teoría performativa del sexo y la sexualidad. Siguiendo a Salih, (2002), tradicionalmente, el construccionismo social ya nos hablaba de la construcción del género, es decir, que las categorías femenino y masculino, o lo que es lo mismo, los roles de género son construcciones sociales y no roles naturales. Pero Butler sobrepasa el género y afirma que el sexo y la sexualidad lejos de ser algo natural son, como el género, algo construido. La autora llega a esta afirmación basándose en las teorías de Foucault ${ }^{15}$, Freud y Lacan. De este último, toma la categoría "forcluido", como aquellas posiciones sexuales que suponen un trauma el ocuparlas; y ante el miedo a habitar alguna de éstas, el individuo se posiciona en una heterosexualidad falogocéntrica, es decir, una heterosexualidad regida por la normativa del imperialismo heterosexual masculino en la que asumir la sexualidad hetero implica asumir un sexo determinado.

\footnotetext{
14 Judith Butler nació en Cleveland, Estados Unidos el 24 de febrero de 1956, es una filósofa post-estructuralista que ha realizado importantes aportes en el campo del feminismo, la teoría queer, la filosofía política y la ética. Su obra más conocida es El Género en disputa. Feminismo y la subversión de la identidad (1990) y Cuerpos que importan. El límite discursivo del sexo (1993), describen lo que hoy se conoce como teoría queer.

15 Principalmente: Foucault, Michel (1982). Historia de la sexualidad 1. La voluntad del saber. México: Siglo XXI. Y Foucault, Michel (1981). Vigilar y castigar: nacimiento de la prisión. México: Siglo XXI.
} 
En su obra fundadora de la teoría queer, la autora llama a cuestionar la categoría del sujeto en una crítica genealógica que analiza las condiciones de los sujetos emergentes en el discurso.

Considerar que las categorías fundacionales del sexo, el género y el deseo son efectos de una formación específica del poder requiere una forma de cuestionamiento crítico que Foucault, reformulando a Nietzsche, denomina "genealogía". La crítica genealógica se niega a buscar los orígenes del género, la verdad interna del deseo femenino, una identidad sexual verdadera que la represión ha mantenido enterrada; la genealogía indaga sobre los intereses políticos que hay que señalar como origen y causa de las categorías de identidad que, de hecho, son los efectos de instituciones, prácticas y razonamientos de origen diverso y difuso. La labor de este cuestionamiento es centrar -y descentrar- esas instituciones definitorias: el falogocentrismo y la heterosexualidad obligatoria. (Butler, 1999: 37-38).

A partir de Butler entonces, el género ya no va a ser la expresión de un ser interior o la interpretación de un sexo que estaba en la persona antes del género. El género para Butler es una construcción social, una serie de discursos que rigen una normatividad dentro de la sexualidad donde no hay acceso directo a la materialidad del cuerpo, el acceso es a través de un imaginario social, sólo se puede acceder a la "verdad" del cuerpo a través de los discursos, las prácticas y las normas que afirman en ese imaginario social, la existencia de un "sexo natural" organizado en una concepción binaria "varón/mujer" con lugares antagónicos y complementarios. Esta concepción creada y construida culturalmente constituye para la autora -siguiendo a Foucault- un dispositivo mediante el cual el género se ha estabilizado dentro de la matriz heterosexual que caracteriza a nuestras sociedades.

Butler en su libro realiza revisiones críticas de las teorías de los feminismos esencialistas de segunda ola, para pasar a hablar de identidades nómadas frente a aquellas fijas, así como para plantear nuevas formas de habitabilidad de los cuerpos en la paradoja que se crea entre lo que es la capacidad de acción del 
individuo y su formación y dependencia con respecto al poder. En la sección "inscripciones corporales, subversiones performativas", basándose en lo señalado por Foucault en Vigilar $y$ Castigar y en Historia de la sexualidad 1, plantea que el límite y la superficie de los cuerpos están construidos políticamente.

No se debería decir que el alma es una ilusión, o un efecto ideológico. Pero sí que existe, que tiene una realidad, que está creada de manera perpetua en torno, en la superficie $\mathrm{y}$ en el interior del cuerpo por el funcionamiento de un poder que se impone sobre aquellos a quienes se castiga. (Foucault, 1981: 36)

En definitiva, la autora propone desnaturalizar los conceptos de sexo, género, deseo y sexualidad por ser construcciones culturales de normas que reprimen y disciplinan a aquellos sujetos que no participan de las mismas. Para ello, formula como estrategia para desnaturalizar y otorgar un significado nuevo a las categorías corporales, explicar y proponer un conjunto de prácticas paródicas fundada en una teoría performativa de los actos de género que tergiversan las categorías del cuerpo, el sexo, el género y la sexualidad y que hacen que éstas adquieran nuevos significados y se multipliquen subversivamente más allá del marco binario (Butler, 1999). Para subvertir los conceptos que oprimen al individuo, la autora propone la creación de actos performativos en torno a la identidad, es decir, una serie de prácticas imitadoras con base en su teoría performativa que acaban creando nuevos significados y se reproducen más allá de cualquier sistema binario.

En esta idea de la performatividad, resulta más atinado referirse a los géneros en plural, inscribiéndose las identidades "trans" que van más allá de cualquier género, exigiendo deconstruir la matriz heteronormativa pretendida como natural y a través de la cual se imponen estereotipos de género considerados "normales". ${ }^{16}$

16 No es una novedad que la rígida división en sólo dos géneros no se corresponde con la realidad. Sin embargo, por ejemplo, las leyes en la mayoría de países del mundo ignoran que 
En el primer capítulo, titulado "Sujetos de sexo/género/ deseo", emprende la tarea de reconsiderar el estado de "la mujer" como el sujeto político del feminismo, examinar críticamente la distinción entre sexo y género y entender el falogocentrismo y la heterosexualidad obligatoria como regímenes de poder y discurso.

La autora empieza su argumentación en este capítulo discutiendo una de las premisas fundamentales de gran parte de la teoría feminista: que existe una identidad y un sujeto que requiere representación política y lingüística. En este sentido, cabe preguntarse si tiene sentido pensar en un sujeto previo al ejercicio mismo de la representación. Butler argumenta que la categoría "mujer", e incluso su plural "mujeres", son términos problemáticos y fallidos, que se complican al pensar las sobreposiciones con otros aspectos de la identidad como la clase, la raza, la sexualidad, la etnicidad, entre otros. Asimismo, Butler nota que la universalidad que presume el querer estructurar las políticas feministas por medio de un sujeto unívoco y permanente deviene en la universalidad asumida del sistema patriarcal, borrando de esta forma las particularidades de las relaciones de poder mediadas por el género en diversidad de tiempos y contextos culturales específicos.

Butler sostiene que la afirmación de un patriarcado universal ha perdido credibilidad, la noción de un concepto generalmente compartido de las "mujeres", la conclusión de aquel marco, ha sido mucho más difícil de derribar. Desde luego, ha habido numerosos debates al respecto.

¿Comparten las «mujeres» algún elemento que sea anterior a su opresión, o bien las «mujeres» comparten un vínculo únicamente como resultado de su opresión? ¿Existe una

\footnotetext{
algunos niñxs intersexuales son sometidos a operaciones forzadas. Algunas sociedades están avanzando en el reconocimiento de los derechos de las personas reconociendo un "tercer sexo" o "género neutro". Alemania, Francia, Suecia Australia, Nueva Zelandia, Nepal, Pakistán, Bangladesh, India, Canadá, Malta y Kenia y en algunos estados de los Estados Unidos como California donde se emiten licencias de conducir no binarias " $X$ ". Disponible en: https://www. dw.com/es/en-estos-pa \%C3 \%ADses-se-reconoce-el-tercer-g \%C3 \%A9nero/a-41306656 En mi opinión, debería desaparecer la categoría "sexo" en todos los documentos públicos.
} 
especificidad en las culturas de las mujeres que no dependa de su subordinación por parte de las culturas masculinistas hegemónicas? ¿Están siempre contraindicadas la especificidad y la integridad de las prácticas culturales o lingüísticas de las mujeres y, por tanto, dentro de los límites de alguna formación cultural más dominante? ¿Hay una región de lo "específicamente femenino", que se distinga de lo masculino como tal y se acepte en su diferencia por una universalidad de las "mujeres" no marcada y, por consiguiente, supuesta? La oposición binaria masculino/femenino no sólo es el marco exclusivo en el que puede aceptarse esa especificidad, sino que de cualquier otra forma la "especificidad» de lo femenino, una vez más, se descontextualiza completamente y se aleja analítica y políticamente de la constitución de clase, raza, etnia y otros ejes de relaciones de poder que conforman la "identidad" y hacen que la noción concreta de identidad sea errónea. (Butler, 1999: 50).

La intención de Butler aquí, es argumentar que las limitaciones del discurso de representación en el que participa el sujeto del feminismo socavan sus supuestas universalidad y unidad. De hecho, la reiteración prematura en un sujeto estable del feminismo provoca inevitablemente un gran rechazo para admitir la categoría. Estos campos de exclusión ponen de manifiesto las consecuencias coercitivas y reguladoras de esa construcción, aunque ésta se haya llevado a cabo con objetivos de emancipación. En realidad, la división en el seno del feminismo y la oposición paradójica a él por parte de las "mujeres" a quienes dice representar, muestran los límites necesarios de las políticas de identidad. La noción de que el feminismo puede encontrar una representación más extensa de un sujeto que el mismo feminismo construye, tiene como consecuencia para Butler, que los objetivos feministas podrían frustrarse si no tienen en cuenta los poderes constitutivos de lo que afirman representar. Este problema se agrava si se recurre a la categoría de la mujer sólo con finalidad "estratégica", porque las estrategias tienen -para la autora- significados que sobrepasan los objetivos para 
los que fueron creadas. En este caso, "la exclusión en sí puede definirse como un significado no intencional, pero con consecuencias, pues cuando se amolda a la exigencia de la política de representación de que el feminismo plantee un sujeto estable, ese feminismo se arriesga a que se lo acuse de tergiversaciones inexcusables" (Bulter, 1999: 51).

\section{II.1.2. Mujeres, raza y clase ${ }^{17}$}

Dentro de la tercera ola, se ubica la teoría y la acción de Angela Davis. Exponente del feminismo negro en Estados Unidos, en su obra trata de develar las causas que llevaron a que las reivindicaciones de las mujeres negras fueran sistemáticamente invisibilizadas $^{18}$.

17 Los trece ensayos que componen Mujeres, raza y clase son: 1. El legado de la esclavitud: modelos para una nueva feminidad. 2. El movimiento antiesclavista y el nacimiento de los derechos de las mujeres. 3. La clase y la raza en los albores de la campaña por los derechos de las mujeres. 4. El racismo en el movimiento sufragista de las mujeres. 5. El significado de la emancipación para las mujeres negras. 6. Educación y liberación desde la perspectiva de las mujeres negras. 7. El sufragio femenino a comienzos del siglo XX: la progresiva influencia del racismo. 8. Las mujeres negras y el movimiento de los clubes. 9. Mujeres obreras, mujeres negras y la historia del movimiento sufragista. 10. Mujeres comunistas. 11. Violación, racismo y el mito del violador negro. 12. Racismo, control de la natalidad y derechos reproductivos. 13. El trabajo doméstico toca su fin: una perspectiva de clase. En ellos recorre los mitos, las presencias y las ausencias de la historia de las mujeres negras en Estados Unidos y la necesidad de dar visibilidad a las demandas no mayoritarias para poder seguir avanzando en el terreno teórico y en el práctico. La autora desmonta el mito del violador negro y explica que "fue una invención claramente política", propaganda construida con el fin de consolidar y justificar los linchamientos, como método de 'contrainsurgencia' destinado a evitar que los negros alcanzaran sus derechos.

18 Angela Davis nació en Birmingham, Alabama, Estados Unidos el 26 de enero de 1944. Es una filósofa, política marxista, activista afroamericana antirracista y feminista, y profesora del Departamento de Historia de la Conciencia en la Universidad de California en Santa Cruz de Estados Unidos. En 1969 fue expulsada de la Universidad de California, donde impartía clases de Filosofía como profesora auxiliar (habiendo sido alumna de Herbert Marcuse) al descubrirse su afiliación al Partido Comunista de Estados Unidos. Estuvo relacionada con el movimiento Panteras Negras. Se vio también involucrada en el caso de "Los hermanos de Soledad", por el cual fue acusada de asesinato y secuestro en 1972. Este caso alcanzó repercusión mundial, lo que impidió su condena. Quedó absuelta en 1973. En 1974 pasó a formar parte del Comité Central del Partido Comunista de los Estados Unidos. En 1976, tras publicar su autobiografía, regresó a la enseñanza. Años más tarde, en 1984, presentó junto a 
La importancia política del libro Mujeres, raza y clase se destaca porque articula una triple perspectiva en la lucha por combatir la exclusión racial, de género y de clase.

En su libro se pregunta por qué las reivindicaciones de las mujeres negras a lo largo de la historia del feminismo han sido sistemáticamente invisibilizadas, siendo Estados Unidos la cuna de las luchas feministas en el siglo XX. A través de una genealogía por distintos hitos y movimientos políticos, analiza las estrategias de lucha de las mujeres negras. Los principales reclamos de Angela Davis son: la necesidad de estudiar el papel de las mujeres negras norteamericanas separado de las mujeres en general, sobre todo de la visión dominante de la mujer blanca urbana de clase media, y la necesidad de dar visibilidad a preocupaciones específicas de grupos particulares dentro del contexto cultural y económico dominante.

La autora desmantela el discurso totalizador y patriarcal no sólo para contar algunos acontecimientos históricos de la emancipación de las mujeres, sino para hacerlo desde la perspectiva de una mujer, negra y comunista. ¿Qué significa entonces, ser mujer, ser negra, ser comunista? Señala que la situación de las mujeres negras en Estados Unidos sólo puede entenderse si se la contempla dentro del contexto de la población negra en general y su lucha contra el esclavismo.

Davis recorre las luchas feministas norteamericanas desde principios del siglo XIX hasta mediados del siglo XX, pasando por los roles de las mujeres negras esclavas, hasta los roles $\mathrm{y}$ realidades de las modernas mujeres negras debilitadas e invisibilizadas por el sistema patriarcal y capitalista, pero también por los movimientos feministas predominantes, centrados en las realidades de las mujeres blancas y burguesas. La autora revindica así, los errores del movimiento feminista dominante al olvidar las exclusiones y las opresiones étnicas, económicas y sexuales,

Gus Hall, el entonces líder del Communist Party USA, su candidatura a la vicepresidencia de su país. Disponible en: https://www.youtube.com/watch?v=1zBDpGI9RTw; https://www. youtube.com/watch?v=6JRHu5eY0J0; https://www.youtube.com/watch?v=tG1IUvUPHe8 
en una crítica transversal al sistema capitalista. Este feminismo, que tiene en cuenta la interseccionalidad ${ }^{19}$, se constituye así, en un vector de crítica y desarticulación radical de las estructuras transversales de control político y social que van desde el espacio doméstico hasta las cárceles, pasando por los estatutos que confieren ciudadanía, trabajo, identidad o pertenencia.

La autora relata el caso de 1833 de Prudence Candrall, una profesora blanca de Connecticut, que recibió toda la atención mediática por aceptar a una niña negra en la escuela. Candrall fue desprestigiada por abrir una escuela donde pudieran matricularse niñas negras.

La inquebrantable defensa de Prudence Candrall de los derechos de las personas negras a recibir educación constituía un ejemplo espectacular, más potente del que jamás se podía haber imaginado, para las mujeres blancas que estaban sufriendo las punzadas del alumbramiento de una conciencia política. De manera lúcida y elocuente, sus actos transmitían inmensas posibilidades de liberación si las mujeres blancas en masa estrechasen las manos de sus hermanas negras. (Davis, 1981: 45)

Angela Davis recorre históricamente la participación en calidad de oyente de Lucrecia Mott en el Congreso fundacional de la Sociedad Antiesclavista Americana. Destaca el papel histórico de las hermanas Grimke, quienes abordaron el abolicionismo en relación con la dominación hacia las mujeres.

19 El término fue acuñado en 1989 por la abogada afroestadounidense Kimberlé Crenshaw en el marco de la discusión de un caso concreto legal, con el objetivo de hacer evidente la invisibilidad jurídica de las múltiples dimensiones de opresión experimentadas por las trabajadoras negras de la compañía estadounidense General Motors. Con esta noción, Crenshaw esperaba destacar el hecho de que en Estados Unidos las mujeres negras estaban expuestas a violencias y discriminaciones por razones tanto de raza como de género y, sobre todo, buscaba crear categorías jurídicas concretas para enfrentar discriminaciones en múltiples y variados niveles. Si bien la aplicación de la interseccionalidad ha sido y continúa siendo contextual y práctica, a partir de ella se creó una teoría de la opresión general. En los contextos académicos anglófonos, la interseccionalidad parece haberse convertido en el tropo feminista más difundido para hablar ya sea de identidades o de desigualdades múltiples e interdependientes (Viveros Vigoya, 2016). 
El 10 y 20 de julio de 1948 se celebrará la convención de Séneca Falls donde participará Lucrecia Mott, sin embargo, serán Elisabeth Cady Stanton junto con Frederick Douglass quienes realizarán propuestas reveladoras con un contenido radical para el momento como el sufragio femenino. Además, Douglass fue el primero en hacer un llamamiento a los derechos de las mujeres dentro del movimiento de liberación de la población negra. ${ }^{20}$

Pero, ¿Qué significaba todo esto? ¿De qué modo se definía la cuestión de la igualdad de las mujeres, al margen de la cuestión del sufragio que había suscitado el desdén de la opinión pública hacia la Convención de Séneca Falls? Las reivindicaciones esbozadas en la Declaración de Sentimientos y las demandas planteadas en las resoluciones, ¿reflejaban, verdaderamente, los problemas y las necesidades de las mujeres de Estados Unidos? (Davis, 1981: 61).

Davis critica que quienes redactaron el documento, aunque incidieran en los aspectos negativos del matrimonio y reivindicaran la independencia de la mujer, lo hacían únicamente desde la perspectiva de la mujer blanca de clase media, sin considerar la situación de las mujeres obreras, o de las mujeres negras. Una vez más, Angela Davis pone el acento en la raza y en la clase. El feminismo, entendido como la lucha común entre todas las mujeres del mundo por la igualdad social, no se concibe sin la lucha de clases. En la Convención de Séneca Falls no hubo ninguna mujer negra.

Davis resalta de tal forma, la discriminación racial operada por el feminismo dominante, para afirmar un nuevo programa

20 La Declaración de Seneca Falls también conocida como la Declaración de Sentimientos y Resoluciones de Seneca Falls que surgió como resultado de la reunión, fue firmado por sesenta y ocho mujeres y treinta y dos hombres de diversos movimientos y asociaciones políticas de corte liberal y próximos a los círculos abolicionistas, lideradas por Elizabeth Cady Stanton y Lucretia Mott para estudiar las condiciones y derechos sociales, civiles y religiosos de la mujer. Consta de doce decisiones e incluye dos grandes apartados: las exigencias para alcanzar la ciudadanía civil para las mujeres y los principios que deben modificar las costumbres y la moral. Once de las decisiones fueron aprobadas por unanimidad y la número doce, la que hace referencia al voto, por una pequeña mayoría. 
feminista, basado en una alianza transversal que sea diverso e inclusivo, criticando las exclusiones de raza, género, clase y sexualidad, planteándolo como un proyecto de emancipación colectiva.

\section{II.1.3. ¿Es el multiculturalismo malo para las mujeres?}

Hernández Castillo (2003) afirma que la politóloga Susan Moller Okin ${ }^{21}$ (1999), profesora de la Universidad de Stanford, reunió a través de la pregunta a científicos sociales defensores y detractores del multiculturalismo para discutir las implicaciones que puede tener para las mujeres el reconocimiento de los derechos colectivos de "minorías". En esta antología, la autora argumenta que existe una tensión muy fuerte entre el multiculturalismo y el feminismo, si consideramos que el primero parte de una reivindicación de las culturas de las minorías étnicas, mientras que el feminismo asume como principio la crítica a cualquier cultura patriarcal.

La autora analiza la poligamia, el matrimonio forzado, la mutilación genital femenina, el castigo de las mujeres por ser violadas, el acceso diferencial de hombres y mujeres a la atención médica y la educación, los derechos desiguales de propiedad, reunión y participación política, la vulnerabilidad desigual a la violencia. Okin afirma que estas prácticas y condiciones son estándar en algunas partes del mundo, lo que la hace preguntarse: "¿Las demandas de multiculturalismo, y ciertos derechos de grupos minoritarios en particular, los hacen más propensos a continuar y extenderse a las democracias liberales? ¿Existen conflictos fundamentales entre nuestro compromiso con la equidad de género y nuestro creciente deseo de respetar las costumbres de las culturas o religiones minoritarias?".

21 Susan Moller Okin (Auckland, 19 de julio de 1946 - Lincoin, 3 de marzo de 2004), fue una filósofa política feminista liberal nacida en Nueva Zelanda y nacionalizada estadounidense, autora de numerosos artículos y libros sobre filosofía política feminista. Sostiene que la preocupación por la preservación de la diversidad cultural no debe eclipsar la naturaleza discriminatoria de los roles de género en muchas culturas minoritarias tradicionales. Durante su carrera, recibió varias distinciones y premios por su trayectoria académica y sus obras. 
Sobre la premisa de sostener que la gran mayoría de las culturas y las tradiciones son patriarcales y discriminan o excluyen a las mujeres, la autora afirma que el multiculturalismo es malo para las mujeres. Comienza argumentando que algunos derechos grupales pueden, de hecho, poner en peligro a las mujeres. Señala, por ejemplo, que el gobierno francés les dio a miles de inmigrantes varones un permiso especial para traer múltiples esposas al país, a pesar de las leyes francesas contra la poligamia y la amarga oposición de las esposas a la práctica. Okin argumenta que, si estamos de acuerdo en que las mujeres no deberían verse en desventaja debido a su sexo, no deberíamos aceptar los derechos grupales que permiten prácticas opresivas con el argumento de que son fundamentales para las culturas minoritarias cuya existencia podría verse amenazada.

La autora muestra la tensión entre el feminismo y el multiculturalismo a través de un caso:

Durante 1980 el gobierno francés permitió a los hombres inmigrantes traer múltiples esposas al país, al punto que se estimó que 200.000 familias en París son actualmente polígamas. Cualquier sospecha de que la preocupación oficial acerca del uso de las pañueletas en la cabeza se debía a un impulso hacia la igualdad de género, quedó desvirtuada con la fácil política permisiva acerca de la poligamia, a pesar de la carga que semejante práctica impone en la mujer y a pesar de las alertas expresadas por las mujeres de las culturas pertinentes. Acerca de este hecho la oposición política efectiva no fue contundente. Pero una vez que los periodistas finalmente entrevistaron a las esposas, descubrieron lo que el gobierno debería haber aprendido antes, las mujeres afectadas por la poligamia, lo tomaban como una institución inevitable y a penas tolerable en sus países africanos de origen, pero imposible de soportar en un contexto francés. Apartamentos repletos, falta de privacidad para cada esposa, generaba inmensa hostilidad, resentimiento e incluso violencia entre esposas y contra los hijos de las otras esposas. (Moller Okin, 1999: 2-3). 
Moller Okin sostiene que la permisividad del gobierno francés hacia la poligamia, muestra una gran tensión entre el feminismo y el interés del multiculturalismo para la protección de la diversidad cultural.

Pienso que nosotros -aquellos de nosotros que nos consideramos progresistas políticamente y opuestos a todas formas de opresión- asumimos fácilmente que feminismo y multiculturalismo son cosas buenas que se concilian fácilmente. Yo quisiera argumentar que hay una considerable tensión entre ellos, más precisamente entre compromisos feministas y multiculturalistas con derechos grupales para las minorías culturales. En pocas palabras explicaré el término y el punto de mi argumento. Feminismo significa que las mujeres no deben tener desventajas por su sexo, que debe ser reconocida su dignidad humana igual a la de los hombres y que deben tener la oportunidad de vivir tan plena y libremente como los hombres. Multiculturalismo es difícil de definir, pero por lo que me atañe, es el reclamo en el contexto de libertades democráticas básicas, de culturas minoritarias o maneras de vida no suficientemente protegidas en la práctica de asegurar el ejercicio de los derechos individuales de sus miembros. Como consecuencia de lo anterior deben ser protegidos a través de derechos especiales de grupo o privilegios. (Moller Okin, 1999: 3).

En el artículo que abre el debate, Moller Okin concluye que las mujeres de estas minorías étnicas (que en muchos casos pueden ser mayorías) "quizá estén mejor si la cultura en la que nacieron se extingue (al integrarse sus miembros a la cultura nacional menos sexista)" (Moller Okin, 1999: 23).

\section{II.1.4. Multiculturalismo y género. Aportes de la democracia deliberativa}

María Luisa Femenías ${ }^{22}$ y Graciela Vidiella ${ }^{23}$ sostienen que los entrecruzamientos entre multiculturalismo y feminismo son tensos y complejos. Para algunos, las demandas multiculturales no hacen sino mantener estructuras discriminatorias en las que 
las mujeres llevan la peor parte. Otros sostienen que, dado que el multiculturalismo reclama el reconocimiento de las diferencias, es la perspectiva idónea para deconstruir las operaciones de dominio ocultas tras la igualdad formal propugnada por el liberalismo.

La tesis que proponen es argumentar a favor de una concepción deliberativa de la democracia, basada en una igualdad sustantiva y sensible tanto a las cuestiones feministas y de género, como a la categoría de reconocimiento, pilar del multiculturalismo, y que además sea compatible con un paradigma universalista de derechos morales.

Las autoras se preguntan:

(...) ¿cuáles son las razones normativas que justifican el resguardo, sin más, de las culturas? Incluso, ¿todas las

22 María Luisa Femenías (Buenos Aires, 18 de agosto de 1950) es una filósofa feminista argentina, académica, investigadora y escritora. Pionera en los estudios de género en Argentina, en sus proyectos de investigación ha trabajado la noción de sujeto e identidad centrándose en cuestiones de multiculturalidad, exclusión y conocimiento situado además de sobre la violencia contra las mujeres en América Latina. Su trabajo fue clave para la consolidación del “Centro Interdisciplinario de Estudios de Género" de la Universidad Nacional de la Plata. En 2016 recibió el premio nacional Fundación Konex. Estudió Filosofía en la Universidad de Buenos Aires y se doctoró en Filosofía Teórica en la Universidad Complutense de Madrid con una tesis dirigida por Celia Amorós sobre el pensamiento aristotélico publicada en 1996 con el título de Interioridad y Exclusión: Un modelo para desarmar. Buenos Aires, 1996.

Disponible en: https://es.wikipedia.org/wiki/Mar \%C3 \%ADa_Luisa_Femen \%C3 \%ADas.

23 Graciela Vidiella nació el 01/10/1952. Doctora en Filosofía (UBA). Actualmente es Profesora Adjunta de Ética en la Facultad de Humanidades u Ciencias de la Educación (UNLP) y es Profesora Titular de Ética de la Facultad de Humanidades y Ciencias (UNL). Publicó los siguientes libros: El derecho a la salud, Universalismo y Particularismo (en colaboración); Breviario de Ética (en colaboración con Osvaldo Guariglia y Los derechos fundamentales (en colaboración), Ética, estos dos últimos destinados a la enseñanza secundaria. Fue directora de la Maestría en Ética Aplicada de la Facultad de Filosofía y Letras y del Departamento de Filosofía de la misma institución. Participó en numerosos proyectos de investigación de la UBA y de la Agencia Nacional de Investigaciones Científicas y Técnicas, de la UNLP y de la UNL. Actualmente dirige: Problemas en torno a la legitimidad en la teoría de la democracia en la Universidad Nacional del Litoral y Democracia deliberativa. Fundamentos, requisitos y limitaciones en la Universidad Nacional de La Plata. En 1997 obtuvo el Segundo Premio en Cuento en el concurso Avón con la Mujer en las Letras. Disponible en: https://www. fundacionkonex.org/b2765-graciela-vidiella 
culturas minoritarias merecen ser protegidas de la misma manera? ¿Qué ocurre con las que tienen rasgos manifiestamente autoritarios, xenófobos o las que se niegan a escolarizar a los niños? En especial referencia al tema que nos convoca, ¿qué actitud adoptar ante aquellas culturas que subordinan a las mujeres o, aún peor, aceptan y/o promueven la mutilación genital, la lapidación, la violación iniciática, el matrimonio infantil, u otros? En el marco de estos ejemplos, podemos preguntarnos, ¿todos los rasgos o componentes de una cultura son igualmente defendibles? Además, como es fácil advertir, se pueden distinguir diferencias idiosincráticas en cada cultura y aspectos diferenciales casi al infinito; el problema es saber - como señalan entre otras Nancy Fraser y Seyla Benhabib- cuáles son relevantes y cuáles no, cuáles generan otros tipos de exclusiones o discriminaciones y cuáles no lo hacen. (Femenías y Vidiella, 2017: 24-35)

Las autoras sostienen que son preguntas cuyas respuestas son claramente complejas. Porque, además, bien puede sostenerse que -como lo señala, por ejemplo, Sophie Bessis (2002: 18)- en las democracias liberales las mujeres también ocupan un lugar subordinado Admitida esta observación, las autoras consideran que ello no constituye un obstáculo para reconocer que existen prácticas ancestrales en otros grupos, tales como las mencionadas, que reportan a las mujeres la máxima discriminación y destrato. La discriminación y la subordinación no son una cuestión de todo o nada, sino de una compleja gama de matices.

Citando a Seyla Benhabib (2006: 151), las autoras consideran que las culturas no son compartimentos estancos y que es epistemológicamente incorrecto pretender encerrarlas bajo un concepto que tenga resabios de esencialismo. Pese a ello, y al mismo tiempo, sostienen que "es necesario tener muy presente que existen prácticas e identificaciones culturales marcadamente patriarcales, donde el sometimiento de las mujeres es mucho mayor que en otros grupos identitarios" (Femenías y Vidiella, 2017: 29). 
Parten del presupuesto siguiente:

Es importante tener en cuenta que la doble identificación étnica y genérica puede producir fuertes tensiones: es frecuente que una mujer perteneciente a determinada minoría étnica no sólo reciba un reconocimiento degradado de la cultura hegemónica en la cual está inserta (racismo), sino también que el reconocimiento que le depara su propia cultura la marque como un ser humano inferior o sólo apto para ciertas tareas, como la gestación y la crianza (sexismo) y, en casos extremos, incluso que la haga objeto de rituales que contradicen los derechos humanos. (Femenías y Vidiella, 2017: 31).

Las autoras ejemplifican su postura con el caso de la niña wichí de doce años embarazada de su violador. Señalan que este tipo de situaciones lleva a algunas teóricas a afirmar que el multiculturalismo es malo para las mujeres, citando a Susan Moller Okin.

Femenías y Vidiella señalan que el multiculturalismo surgió como un movimiento reivindicativo de minorías marginadas por culturas dominantes. Bajo su amparo se cobijaron los nuevos movimientos sociales que constituyen las formas actuales de luchas políticas, con resignificaciones aceleradas de los símbolos tradicionales de sometimiento y de exclusión. Las autoras sustentan su punto de vista en tres ejes normativos: el reconocimiento, la diferencia y la cuestión de los derechos.

Me interesa aquí llevar el análisis al punto 3 "Identidad/ diferencia”, donde las autoras sostienen que a su juicio, lo que está en juego en esta cuestión es la elección entre un criterio normativo universalista e igualitario y otro particularista. Su postura es que la identificación con un determinado grupo puede favorecer la autoestima de las personas y ayudar a que se organicen políticamente, ganen el espacio público y así se hagan visibles. Pero, como contra cara, -sostienen- "también es cierto que esas identificaciones grupales pueden ejercer coacción y coartar la libertad individual de sus propios miembros. Esto les ocurre muchas veces a las mujeres" (Femenías y Vidiella, 2017: 34). 
Citando a Nancy Fraser (1995) reemprenden la pregunta: "¿Cómo, puestas a elegir entre género y etnia, las mismas mujeres optan por su identidad étnica aún en contra de sus propios intereses?". Las autoras responden que se trata claramente del caso de la víctima-cómplice, como lo denominara Simone de Beauvoir hace más de sesenta años. Sostienen que la elección se basa en el concepto de "preferencias adaptativas" elaborado por J. Elster (1988: 42), que ayuda a explicar no sólo por qué las conductas de sometimiento son muchas veces tan difíciles de modificar, sino también por qué las personas subyugadas parecen prestar su asentimiento. Según Elster, las preferencias adaptativas son endógenas; es decir, no son ni fijas ni estables, sino que se adaptan a una amplia gama de factores, tales como el contexto en el cual se expresan, en general, las reglas legales existentes de una cultura.

Las autoras concluyen sobre el punto que:

Al respecto, las mujeres en tanto que individuos desaventajados en sociedades estratificadas, las minorías en las sociedades intolerantes, los trabajadores explotados en las economías explotadoras, tienden a aceptar sus privaciones como resultado de su necesidad de sobrevivencia. Así adaptan sus deseos y expectativas a aquello que consideran factible. Claramente este ha sido el caso de las mujeres a lo largo de la historia. Estas "preferencias" son estrategias para reducir las disonancias cognitivas. En los casos de discriminación racial o de género (y de la tensión entre ambas), suele registrarse un fenómeno paradójico que podemos explicar mediante las preferencias adaptativas: los más favorecidos culpan a las víctimas de su situación, y éstas asumen que el daño es merecido o, por lo menos, que deberían haberlo previsto o evitado. La cultura de la culpa, en la que mayormente se socializa a las mujeres, contribuye significativamente a ello. En suma, cuando se perciben las injusticias como predecibles y parte de un orden naturalizado, se tornan más tolerables. (Femenías y Vidiella, 2017: 35) 
Dicen que las mujeres o los grupos e individuos desaventajados inmersos en este flujo de preferencias adaptativas no son capaces de articular preferencias autónomas. Ejemplifican su postura en la práctica del sati en la India, la mutilación genital femenina en Mali, Gambia o Mauritania. Sostienen que estas mujeres "optando por su identidad étnica aun en contra de sus intereses”, cierran un perverso círculo de violencia de género. Para las autoras, para que exista una elección identitaria genuina se requeriría que las mujeres puedan realizar un examen crítico de su propia cultura y que tuvieran opciones genuinas disponibles a fin de que la identificación con una cierta cultura sea auténtica elección.

En cuanto al acápite 4 "Derechos grupales/individuales", las autoras analizan dos casos de colisión entre derechos grupales y derechos individuales sucedidos en Estados Unidos: uno de la comunidad amish contra el Estado de Wisconsin; y otro de Julia Martínez del Pueblo de Santa Clara. Concluyen que no hay razón suficiente para admitir derechos colectivos. Señalan:

Además de producir superpoblación en el conjunto de los derechos y acarrear no poca confusión conceptual, no hallamos un buen argumento que muestre que los derechos colectivos superan el test de género o test de la situación de las mujeres. Esto no significa que no reconozcamos la importancia de la preservación de culturas minoritarias a través de la enseñanza de su propia lengua, de la protección de sus manifestaciones culturales, u otras medidas de ese tenor. Tampoco estamos en desacuerdo con dotar a las minorías culturales con derechos especiales de representación, con cupos étnicos en la educación (como ocurre en Brasil con los "negros»), en el mercado de trabajo para personas con capacidades diferentes o en la política (cupo femenino y paridad). Pero consideramos que el modo correcto de defender esas políticas no es a través de la idea de derechos colectivos, sino de derechos individuales a la igualdad de oportunidades. Las personas integrantes de esos grupos no gozan de igualdad de oportunidades y 
de reconocimiento porque están en inferioridad de condiciones respecto del resto de los ciudadanos y, en el caso de las mujeres, la mayoría de las veces, respecto de los propios miembros varones de sus grupos étnicos de pertenencia (Femenías Vidiella, 2017: 38).

En el punto 5 "la democracia deliberativa", las autoras esbozan los lineamientos generales de una democracia deliberativa que, a su entender, supera las objeciones que los defensores de la política de la diferencia realizan a la democracia liberal, en particular a su interpretación de la igualdad. La basan en un conjunto de derechos básicos civiles y políticos, generalmente brindados por las constituciones que, en la práctica resultan meramente formales para los ciudadanos que pertenecen a los grupos desaventajados. Sostienen que su versión "pone el acento en la inclusión de personas social y económicamente sumergidas en las minorías y es sensible a las cuestiones de género" (Femenías y Vidiella, 2017: 39). Aseguran que el mejor modo de organizar el ejercicio del poder político es que éste pueda verse como el resultado libre y razonado de un procedimiento deliberativo entre personas consideradas como libres e iguales. Hay tres características distintivas de la teoría deliberativa en su versión habermasiana, que las autoras toman en cuenta: la primera es la idea de esfera pública, situada en la sociedad civil, que constituye el espacio de formación de la opinión y de la voluntad, donde los ciudadanos producen discursos al tratar sus asuntos comunes. La segunda es la idea de legitimidad proveniente de la ética del discurso: "Sólo son válidas las normas y arreglos institucionales normativos que pueden acordarse entre todos los interesados de acuerdo con situaciones de argumentación específicas llamadas discursos". La tercera es la idea de la doble vía política, donde intervienen por una parte las instituciones formales, tales como la legislatura y el poder judicial, y por la otra, el espacio informal de la esfera pública, donde se incluyen los discursos de la sociedad civil en sus distintas variantes, tales como las actividades y luchas de los movimientos sociales, los medios de comunicación y las asociaciones de la sociedad civil. 
Para evitar las críticas al sesgo elitista de la teoría deliberativa, indican que se debe evitar "la pobreza política" de la que habla Bohman (1997: 321-348), que impide que los grupos de ciudadanos participen de manera efectiva en los procesos democráticos, con las siguientes consecuencias: exclusión pública, donde los grupos empobrecidos políticamente no les resulta posible evitar la exclusión pública porque no pueden iniciar la deliberación; y la inclusión política, ya que los empobrecidos políticamente son los destinatarios legales de los acuerdos deliberativos sobre los cuales no tienen poder ni influencia. Su silencio es convertido en consentimiento por los poderosos. Las autoras, apuntan que ésta es la situación de las mujeres y ejemplifican con el caso en análisis.

Señalan que:

A fin de clarificar nuestro punto de vista consideremos otro caso de una niña de la comunidad wichí violada por su padrastro en la región de Tartagal, provincia de Salta, Argentina. La madre de la niña denunció ante la justicia a su pareja, hijo del chamán de la comunidad, por haber abusado de su hija de once años y dejarla embarazada. En el expediente judicial consta un acta donde se consigna que la mujer afirmó que había sido amenazada por el cacique de su comunidad: éste le había dicho que, si denunciaba al violador, ella también quedaría presa y, además, sería expulsada de la comunidad. A poco que la niña diera a luz, la madre y algunos miembros del grupo pidieron la libertad del abusador: alegaron que la mujer había sido influenciada a realizar la denuncia por la maestra del colegio al que asistía la niña y que, de acuerdo con sus pautas culturales, los wichí admiten el matrimonio de un hombre con una mujer y su hija (matrimonio privignático). También dijeron que ellos consideran que las chicas, a partir de la menstruación, están en condiciones de elegir compañero sexual, lo que había ocurrido en este caso. Las alegaciones de la defensa del acusado llegaron a la Corte salteña y lograron anular la detención. Esta institución justificó su decisión -con la excepción de una jueza- aduciendo que 
las pautas culturales de la comunidad wichí contemplan el matrimonio privignático y que el acusado no tuvo conciencia de incumplimiento de norma jurídica alguna. Posteriormente el imputado fue nuevamente procesado y permaneció detenido hasta el año 2012. (Femenías y Vidiella, 2017: 43).

Las autoras critican algunas voces de la "la esfera pública": la de una antropóloga de la Universidad de Buenos Aires dedicada a los derechos indígenas que defendió la inocencia del acusado argumentando que se había guiado por costumbres ancestrales de su comunidad y que había tenido una actitud de responsabilidad y protección hacia la madre y la hija. Otra colega de la misma universidad, también especialista en la temática de los derechos de los pueblos originarios, arguyó que entre los wichí una chica es mujer desde que tiene su primera menstruación. Sostuvo asimismo que durante el proceso no había sido consultado el líder de la comunidad y que ése había sido un error del sistema judicial, ya que, según su conocimiento, los líderes comunitarios tienen formas de resolver los conflictos, aunque en ese caso no había existido conflicto alguno. Por su parte, una abogada, profesora de Derechos de los Pueblos Originarios, aseveró que en el proceso judicial se dieron por supuestas las normas de la cultura occidental dominante, lesionando el principio democrático de igualdad, que requiere respetar las diferencias.

Las autoras contrastan estas voces "expertas" con otras opiniones vertidas sobre el mismo tema, incluyendo la de una mujer referente del pueblo wichí salteño, quien señala que "esta crueldad, este abuso cometido por un miembro de la comunidad, de un clan /.../ [e]s una aberración que los científicos estos que entran por la puerta grande de nuestras comunidades, de nuestro pueblo, se pongan a la par de los abusadores y utilicen a la ciencia para más sometimiento".

Femenías y Vidiella contraponen en el caso los argumentos multiculturalistas a ultranza, esgrimidos por algunos especialistas, con su punto de vista de la democracia deliberativa. 
Dicen que los y las antropólogas referidas, en nombre del reconocimiento igualitario de las diferencias, incurrieron en una serie de consideraciones sobre cuyas consecuencias negativas para las mujeres -en este caso las mujeres y niñas integrantes de un grupo especialmente vulnerable como la etnia wichí- han llamado la atención a lo largo del trabajo. Sostienen que los puntos de vista que las académicas referidas tomaron en cuenta eran los de los líderes varones de la comunidad y no tomaron en cuenta que el cambio de opinión de la madre de la niña violada pudo deberse al miedo causado por las amenazas que le prodigaron los propios miembros de su comunidad.

Desde el punto de vista deliberativo que defienden las autoras, la consideración del caso es bien distinta.

En primer lugar, hay que preguntarse por los derechos de la niña wichí en tanto individuo y menor de edad; en segundo lugar, si las capacidades mínimas requeridas para poder participar de una deliberación pública de la afectada estaban dadas. Al respecto puede alegarse que se trata de una niña, y que por tanto no puede disfrutar de las capacidades que puede poseer una persona adulta. Esto es cierto, pero la pregunta correcta que corresponde realizar en este caso es: ¿permiten los funcionamientos actuales de la niña el desarrollo futuro de las capacidades que la harían una persona capaz de participar en condiciones de igualdad en una discusión pública? Claramente no es así porque la niña fue violada. Dados los supuestos de la democracia deliberativa resulta imposible defender, en aras de la discriminación que sufre un grupo marginado, el desconocimiento consciente de la violencia que sufre al menos uno de sus miembros. (...) la Convención de los Derechos del Niño, que Argentina ha incorporado a su legislación, es un documento jurídico valioso que no puede ser objetado en aras de defender cualquier tipo de prácticas culturales, incluyendo las de culturas sumergidas. (Femenías y Vidiella, 2017: 44-45).

Las autoras concluyen que la introducción del punto de vista de la democracia deliberativa permite, no quedar atrapadas 
entre la Escila de discriminar, y a veces criminalizar, las costumbres de culturas no hegemónicas, como se le critica a la democracia liberal, y la Caribdis de la tolerancia a ultranza de un multiculturalismo sin matices.

\section{II.1.5. "Mujeres blancas buscando salvar a mujeres color cafe": desigualdad, colonialismo jurídico y feminismo postcolonial}

En este artículo Karina Bidaseca ${ }^{24}$ analiza el fallo de la Corte de Salta en el caso "Fabián Ruiz". La tesis de la autora se centra en sostener la existencia de un colonialismo jurídico en el tratamiento del caso por parte del Estado argentino y, en términos de colonialismo discursivo al tratamiento recibido por determinados espacios de poder. Se ensaya lo que la autora llama una "teoría de las voces" desde la conceptualización de Aníbal Quijano sobre la "colonialidad del poder" que incluye el tratamiento de la política de la subjetivación en curso, y se problematizan los límites del feminismo académico para pensar el contexto de la "colonialidad" y lo que se denomina "retórica salvacionista": los continuos intentos de algunas voces feministas de silenciar a las mujeres de color/no blancas o bien, de hablar por ellas.

El propósito de la autora es introducir la narrativa femenina de la subalternización y reflexionar sobre el colonialismo jurídico en las condiciones actuales de dar muerte simbólica a otras subalternas, las mujeres indígenas. Desde el feminismo postcolonial problematiza los límites del feminismo académico para

24 Posdoctora en Ciencias Sociales, Niñez y Juventud por el Centro de Estudios Avanzados en Niñez y Juventud de la alianza CINDE - Universidad de Manizales - Colombia/Pontifícia Universidade Católica de São Paulo - Brasil/El Colegio de la Frontera Norte de México-COLEF. Institución aval: Consejo Latinoamericano de Ciencias Sociales - CLACSO. San Pablo, 27 de marzo 2017. Es Doctora de la Universidad de Buenos Aires, en Ciencias Sociales (2006) con su Tesis Doctoral titulada: "Colonos insurgentes. Acciones colectivas y discursos heréticos por la tierra. Argentina, 1900-2000". Obtuvo el Premio Summa Cum Laude. Es Magíster en Investigación en Ciencias Sociales, Universidad de Buenos Aires (2002) con su tesis titulada "Nómades sin tierra. De hombres y mujeres poblando León Rougés en tiempos de zafra y migraciones". 
pensar la "colonialidad" que pervive en la configuración de las relaciones sociales, luego que el colonialismo como ocupación de territorios por parte de otros Estados ha finalizado. Dentro de una postura (pos) colonial intenta comprender dicha subalternidad femenina en los siguientes términos: por un lado, que racismo y colonialidad constituyen las relaciones de género, y por otro, que el feminismo "blanco" se inscribe en una narrativa imperialista cuando se sostiene en lo que denomina una "retórica salvacionista" de las mujeres color café. Citando a la feminista afroamericana bell hooks, la autora sostiene que permanece en el feminismo contemporáneo la idea de que la raíz de todos los problemas es el patriarcado y que la erradicación de la opresión sexista llevaría necesariamente a la eliminación de todas las demás formas de opresión.

El hablar del patriarcado y no del racismo permite que las feministas blancas sigan actuando como explotadoras y opresoras. Sexismo, racismo y explotación de clase constituyen sistemas interrelacionados de dominación que determinan la agencia femenina (Bidaseca, 2011: 2).

Para demostrar su postura, Bidaseca analiza el caso paradigmático en la República Argentina de "Fabián Ruiz", sosteniendo que en el mismo algunas feministas blancas intentaron silenciar a las mujeres de color/no blancas o bien, de hablar por ellas. La autora expone el caso de la siguiente forma: "Me referiré a uno extremadamente sensible y polémico en la sociedad salteña que, repentinamente, lo selló. Remite a un fallo de la Corte de Salta entre 2005 y 2006, sobre el procesamiento dictado a un hombre indígena de 28 años de la "comunidad" wichí Lapacho Mocho, ubicada al norte de dicha provincia. Fue acusado de haber violado a la hija de su concubina, según la definición de la familia occidental, una "niña de alrededor de 10 años" (pues no se sabe con certeza su edad), quien se convirtió en madre".

Siguiendo la conceptualización de Segato (2007) y Briones (2005) para ubicar los procesos históricos particulares que configuran la matriz de diferencia que ambas autoras definen como "formación nacional o provincial de alteridad", la autora 
incorpora el vocablo "comunidad" confrontando discursivamente a "Estado", aunque advirtiendo su heterogeneidad y agregándole conflictualidad, así como propiciando su necesaria desromantización.

Bidaseca sostiene un colonialismo jurídico en el tratamiento del caso por parte del Estado Argentino y de colonialismo discursivo, cuando las voces "bajas" (Guha, 2002) de las mujeres son fagocitadas, representadas o traducidas por otras voces. Entiende sus voces como instrumento político del sujeto, ensayando, en los pliegues lo que llama una "teoría de las voces" desde la conceptualización de Aníbal Quijano (2000) sobre la "colonialidad del poder" que incluye el tratamiento de la política de la subjetivación en curso.

En el caso en análisis, la autora señala que las voces de la mujer indígena de la comunidad Lapacho Mocho fueron sofocadas.

Relata el caso:

En 2006 un hombre wichí de 28 años, fue acusado de haber violado a la hija de su concubina, una niña de "alrededor de 10 años" quien se convirtió en madre. El hecho, que para el Código Penal es un abuso sexual agravado, para la Corte de la provincia de Salta constituyó en su primer expedido, sin embargo, una pauta étnica y cultural de ese pueblo originario, del mismo modo que para la defensa se trata de una "costumbre ancestral que las mujeres puedan mantener relaciones sexuales consentidas a partir de su primera menstruación, por lo cual no se trataría de una niña sino de una adulta" (Carbajal, 2007). En efecto, la Corte, apoyándose en los estudios de los peritos antropológicos, sostiene que "para juzgarlo debía tenerse en cuenta la aceptación social que entre los wichís tiene que las mujeres mantengan relaciones desde temprana edad" (Ídem). Sin embargo, la Corte que había tomado en su primer momento las pruebas antropológicas aportadas por los peritos, desistió de mantener esa postura; decidió continuar con el procesamiento y encarcelamiento del acusado Qa'tu detenido desde mediados de 2005 en el penal de Tartagal, procesado sin 
juicio, lo cual supera los 2 años establecidos como límite por la justicia. (Bidaseca, 2011: 7)

El caso es desafiante para la autora fundamentalmente porque se trata de una "niña/mujer" cuya voz no puede ser pronunciada y en sentido spivakiano carece de un lugar de enunciación, atrapada entre dos justicias. Afirma que la voz de la "niña/mujer" se encuentra sumergida por el ruido de los mandatos estatistas" (Guha, 2002: 20) y es representada por algunas académicas feministas. "Mientras su vida transcurre en la tensión entre lo privado y lo público se reescribe el guión de su desbastada experiencia identitaria en el lugar fronterizo de la articulación inverosímil: la negociación cae en el lugar de la imposibilidad y la orientalización de su pueblo, en sentido saidiano, puede dejar marcas imborrables en su memoria".

Por eso Bidaseca, señala que su colaboración desde su lugar de privilegio es tratar de llevar el problema al lugar de la discusión que se adeuda a los pueblos indígenas aquí, el de la posibilidad de pensar en las potencialidades del pluralismo jurídico, y de ese modo no seguir profundizando la violencia epistémica, simbólica y material ejercida sobre ellos.

La autora repasa las distintas voces (sofocada de la niña/ mujer, baja de la madre, alta de la Directora de la escuela, alta del Código Penal, altas y hegemónicas de los jueces, baja del acusado, bajas y miméticas de la "comunidad", altas masculinas de peritos antropólogos, altas de las mujeres académicas, alta de la abogada defensora indígena, bajas inaudibles de las mujeres wichí, alta femenina de la niyat). Concluye que el "caso" presentado redunda en profundas y profusas complejidades para el mundo occidental. "Lo paradójico es que no hay ninguna parte lesionada, sólo el Estado responde a esta amenaza contra la moralidad occidental". La autora considera que la importancia del mismo estriba en la falta que muestra: la de una discusión real sobre las posibilidades de construir en nuestro país un Estado pluricultural. Luego de la representación que asumieron las mujeres feministas, pronto cayó en el olvido, "colonizado" por una cuestión predominantemente moral. 
La autora refuerza su postura señalando que "la certeza de la incerteza es no poder determinar si hubo o no delito. Porque la voz de Estela - que es un afuera dentro de un adentro (recordemos que tanto ella como su madre provienen de otra "comunidad")— no puede escucharse, no está su testimonio... éste irrumpe después de cuatro años para pedir la libertad del acusado. Y porque otro afuera, el discurso de la directora, influyó en la madre a hacer la denuncia original".

Bidaseca finaliza su trabajo citando la frase de Gayatri Chakravorty Spivak para la India colonial, "hombres blancos que salvan a las mujeres color café de los hombres color café" (que expresa los discursos orientalistas salvacionistas y a la Mujer como objeto-fetiche), se puede trasladar a un sector de feminismo en el que "mujeres blancas buscan salvar a las mujeres de color café de los hombres color café". Me permito preguntarme: ¿de quién/es necesitan "ser salvadas" las mujeres indígenas?" (Bidaseca, 2011).

\section{Conclusiones}

En este marco de "pandemias" en plural, mis expectativas respecto a este trabajo han sido analizar, problematizar y resignificar los textos seleccionados, para que nos ofrezcan muchas categorías conceptuales y miles de interrogantes desafiando una futura investigación. Los textos elegidos para este ensayo nos conducen hacia otros textos a los fines de determinar desde dónde y desde qué contextos se interpretan y construyen realidades. La sola lectura de los distintos posicionamientos teóricos frente al caso "Fabián Ruiz" desde la antropología, el derecho y la filosofía nos hacen advertir y preguntarnos ¿cómo se construye teoría feminista en la Argentina? Y como sostienen Lerussi y Costa (2018): ¿la producción de conocimiento es una relación de centro-periferia, de recepción-resignificación de las ideas de los feminismos estadounidenses y europeos?

Coherente con estas preguntas y buscando contextualizar, no puedo dejar de observar que este ensayo se enmarca en 
estos tiempos de pandemia. Tiempos raros, abruptos, cargados de desconcierto. En la "sociedad del conocimiento" en la que vivimos, las tecnologías de la información y la comunicación han generado cambios significativos en las formas de percepción y las estrategias de producción, generación y difusión de conocimientos. La informática ha producido en el ámbito de la cultura una revolución semejante a la que produjo la aparición de la imprenta en el siglo XV (Díaz Barriga, 2005). La humanidad atravesada por la revolución tecnológica, asiste con miedo y confusión a la propagación del virus. Antes de la pandemia, otros males ya se encontraban instalados: las desigualdades económicas y sociales entre las personas. Y pareciera que estas desigualdades se consolidarán en desmedro de los grupos vulnerables generando una "pandemia del hambre" 25 . El confinamiento obligatorio pareciera constituir "la única vacuna" conocida hasta el momento para mitigar la propagación de la enfermedad. Comenzamos a normalizar lo que parecía propio de dictaduras: el aislamiento tiene un alto costo para los Derechos Humanos de las personas, sin embargo, parece ser el mejor horizonte para mantener la salud de la mayoría. Y mientras tanto irrumpe con furia otra pandemia: la violencia de género. Las denuncias aumentan en nuestro país durante la cuarentena y, desde que comenzó el confinamiento, el 20 de marzo, se han producido más de 20 feminicidios. "La otra pandemia" coloca en una situación de mayor riesgo a las mujeres y a las niñas, amenazadas doblemente por el Covid-19 y la violencia doméstica.

A pesar de esta distopía, seguiremos esforzándonos en este proceso continuo de lucha por la emancipación y por la igualdad de Derechos Humanos de las mujeres y otras identidades no hegemónicas, para que no sean una mera declaración formal sino una realidad tangible y vivenciada en el aquí y ahora.

25 Basta con observar unas pocas noticias: "La pandemia del hambre: en Salta murieron dos niños y ya son quince en total" 27/3/2020; "Dos hermanitos wichí fallecieron esta semana por desnutrición en Salta", 26/3/2020; "Salta: el hospital de Tartagal desaloja a niños wichís internados en recuperación nutricional", 31/3/2020; "Salta: falleció un adolescente wichí deshidratado y abandonado" 7/4/2020. Disponible en: http://www.laizquierdadiario.com/wichis 
El aporte de Butler a estos interrogantes son el discutir una de las premisas fundamentales de gran parte de la teoría feminista: que existe una identidad y un sujeto que requiere representación política y lingüística. Cabe preguntarse si tiene sentido pensar en un sujeto previo al ejercicio mismo de la representación. Butler argumenta que la categoría "mujer", e incluso su plural "mujeres", son términos problemáticos y fallidos, que se complican al pensar las sobreposiciones con otros aspectos de la identidad como la clase, la raza, la sexualidad, la etnicidad, entre otros. Asimismo, la autora destaca que la universalidad que presume el querer estructurar las políticas feministas por medio de un sujeto unívoco y permanente deviene en la universalidad asumida del sistema patriarcal, borrando de esta forma las particularidades de las relaciones de poder mediadas por el género en diversidad de tiempos y contextos culturales específicos (Butler, 1999).

Podemos analizar si la teoría de la performatividad puede o no ser trasladada a las cuestiones de la etnia/raza y de la clase. En este punto -siguiendo a Butler- se puede aclarar que tras el discurso sobre el género se esconden permanentemente las presuposiciones raciales. Por consiguiente, la pregunta que hay que plantear no es si la teoría de la performatividad puede trasladarse a la raza y a la clase, sino qué le ocurre a dicha teoría cuando trata de lidiar con la raza y con la clase. Muchos de estos debates se han ceñido al lugar que ocupa la "construcción". Butler destaca que ninguna de las explicaciones de la "construcción" servirá, y que estas categorías siempre actúan como fondo la una de la otra y se articulan de forma más enérgica recurriendo la una a la otra.

La autora sostiene que la creencia política de que debe haber una base universal para el feminismo, y de que puede fundarse en una identidad que aparentemente existe en todas las culturas, a menudo va unida a la idea de que la opresión de las mujeres posee alguna forma específica reconocible dentro de la estructura universal o hegemónica del patriarcado o de la dominación masculina. 
La idea de un patriarcado universal ha recibido numerosas críticas en años recientes porque no tiene en cuenta el funcionamiento de la opresión de género en los contextos culturales concretos en los que se produce ${ }^{26}$ (González Vázquez, 2013). Una vez examinados esos contextos diversos en el marco de dichas teorías, se han encontrado "ejemplos" de un principio universal que se asume prima facie. Esa manera de hacer teoría feminista ha sido cuestionada porque intenta colonizar y apropiarse de las culturas no occidentales para respaldar ideas de dominación muy occidentales, y también porque tiene tendencia a construir un "Tercer Mundo" o incluso un "Oriente", donde la opresión de género es sutilmente considerada como sintomática de una barbarie esencial, no occidental. La urgencia del feminismo por determinar el carácter universal del patriarcado -con el objetivo de reforzar la idea de que las propias reivindicaciones del feminismo son representativas- ha provocado, en algunas ocasiones, que se busque un atajo hacia una universalidad categórica o ficticia de la estructura de dominación, que por lo visto origina la experiencia de subyugación habitual de las mujeres (Butler, 1999).

Por su parte, Davis critica también el discurso totalizador y patriarcal no sólo para contar algunos hitos de la emancipación de las mujeres, sino para hacerlo desde la perspectiva de una mujer, negra y comunista. ¿Qué significa entonces, ser mujer, ser negra, ser comunista? Esto sirve para ubicar la premisa de la particularidad de cada "mujer" en cada contexto y con luchas y reivindicaciones distintas, articulándose en el caso de la comunidad wichí -que propusimos para el análisis- en una triple perspectiva en la lucha por combatir la exclusión racial, de género y de clase. Aquí plantearíamos ¿Qué significa entonces, ser mujer, ser wichí, ser integrante de la comunidad Lapacho Mocho?

26 Un estudio clarificador sobre el concepto de patriarcado se puede encontrar en: González Vázquez, Araceli (2013). Los conceptos de patriarcado y androcentrismo en el estudio sociológico y antropológico de las sociedades de mayoría musulmana. Paper 2013 98/3. Collège de France/EHESS. Laboratoire d'Anthropologie Sociale. 
Téngase presente que desde mi experiencia en los talleres "Mujeres de pueblos originarios" del 34 Encuentro Nacional de "Mujeres" $"$, realizado en mi querida ciudad de La Plata, las aseveraciones desde el afuera feminista blanco, mayor, occidental, heterosexual y propietario -en términos de Raffin (2006)-, quedaron relegadas a demandas centradas en la recuperación de los territorios originarios y no en una opresión del "patriarcado".

Argentina como país del "Tercer Mundo" se encuentra lejos de ser un Estado pluricultural que reconozca autonomía territorial y política a los pueblos originarios no obstante estar consagrado jurídicamente en el art. 75 inc. 17 de la Constitución Nacional y en los tratados de Derechos Humanos con jerarquía constitucional en virtud del art. 75 inc. 22, constituyendo un bloque de constitucionalización y convencionalización federal -en términos de Bidart Campos-. Dentro de este panorama general, y dentro del contexto particular del caso "Fabián Ruiz", el objetivo futuro será explorar la situación de las mujeres indígenas en sus contextos particulares, a los fines de corroborar o no la tesis de que éstas son, al mismo tiempo, parte de un colectivo culturalmente desamparado por referencia a la comunidad dominante del Estado en que se insertan, pero también son un grupo vulnerable dentro de sus propias comunidades de pertenencia al quedar expuestas, precisamente por razones culturales, a situaciones de opresión, violencia y vulneración de sus Derechos Humanos. Y este análisis puede intentarse desde la teoría performativa de Butler con las connotaciones de Davis, en el proceso de resignificación que se puede hacer en nuestro país en un campo emergente como es el feminismo argentino.

\footnotetext{
2734 Encuentro Nacional de Mujeres, La Plata, 12, 13 y 14 de octubre de 2019. Previo a su realización y durante la implementación de los talleres se dieron luchas micro políticas sobre el nombre del encuentro, debates que vienen desde Chaco 2017 y Trelew 2018. Es decir, se viene discutiendo lo que menciona Butler y Davis: la cuestión de la identidad de un sujeto/s que requiere representación política y lingüística. Debates acerca de incluir plurinacional y la ampliación de las identidades que componen el nombre del encuentro. La decisión se tomó al cierre del mismo, triunfando la postura respecto a que el 35 Encuentro a realizarse en San Luis Ileve la denominación de "Plurinacional de Mujeres, Lesbianas, Bisexuales, Travestis, Trans, Intersexuales y No Binaries".
} 
Las posiciones teóricas en el caso "Fabián Ruiz" son disímiles en los círculos del derecho y de la antropología. Por una parte, se habla de legislación indígena y normas internacionales de protección de los Derechos Humanos de las niñas, niños y adolescentes, y por otra, se polemiza acerca del papel de los científicos sociales que estudian las comunidades indígenas. Así, por un lado, Femenías y Vidiella (2017: 31) sostienen que: "Es importante tener en cuenta que la doble identificación étnica y genérica puede producir fuertes tensiones: es frecuente que una mujer perteneciente a determinada minoría étnica no sólo reciba un reconocimiento degradado de la cultura hegemónica en la cual está inserta (racismo), sino también que el reconocimiento que le depara su propia cultura la marque como un ser humano inferior o sólo apto para ciertas tareas, como la gestación y la crianza (sexismo) y, en casos extremos, incluso que la haga objeto de rituales que contradicen los derechos humanos". Desde la antropología, voces como las de Tarducci (2013) se alzan para defender esta postura en el caso en análisis.

En la vereda de enfrente, junto con otros estudios en antropología de Carrasco y de Palmer (2012), el de la periodista Carabajal (2007) y la abogada Ramírez (2012), se posiciona Bidaseca que afirma que el tutelaje de los pueblos originarios como práctica colonialista perdura en el tratamiento de los casos que son judicializados. El mentado respeto a la "diversidad" étnica y cultural termina siendo desvirtuado en función de utilizar las propias contradicciones nativas, sus puntos de fuga, y así deslegitimar sus propios sistemas de control social y de impartición de justicia como "bárbaros" dentro de sus jurisdicciones frente a la sociedad mayor; y como "consuetudinarios", lo cual implica minimizar la potencialidad de construir un derecho indígena como "derecho propio", y no como "costumbre jurídica".

Como puede advertirse, es dificultosa la comprensión del caso desde la mirada puramente occidental, como también desde un enfoque feminista esencialista de segunda ola basado en un patriarcado universal. El caso "Fabián Ruiz" desafía los postulados del feminismo y nos hace interrogarnos acerca de la 
construcción de teorías feministas desde Argentina y respecto a las mujeres indígenas de los pueblos originarios que habitan dentro del territorio del Estado nacional. Creo que el enfoque para un entendimiento "intercultural" de los derechos humanos de la mujer indígena -en términos de Boaventura de Sousa Santos (1995)- es la escucha de la mujer real y concreta situada en su comunidad.

En nuestro país son muchos los recorridos feministas realizados que principian un pensamiento y una praxis argentina sobre la temática. La voz de las mujeres argentinas es escuchada por todos los movimientos feministas del mundo y el hecho de que resuene con tanta potencia tiene una explicación: las protagonistas de "Ni una menos" y la campaña por la "Educación sexual para decidir, anticonceptivos para no abortar, aborto legal, seguro y gratuito para no morir", son nietas y bisnietas de una lucha que se remonta al siglo XIX. En la bibliografía se citan algunos escritos que constituyen una plataforma de acción para una variedad de trabajos en nuestra Facultad de Ciencias Jurídicas y Sociales de la UNLP en sus tradicionales funciones -docencia, investigación y extensión- pero deconstruidas a la luz de estos desarrollos.

Como cierre para este ensayo me gustaría expresar que los feminismos argentinos se encuentran o se encontraban en la cresta de esta cuarta ola. Sin embargo, no estamos en el mismo mar ni en la misma tabla. En estos tiempos de pandemia, donde todo es agobiante y contradictorio, parecería que todas las luchas conquistadas han quedado en stand by. Parecería que ha transcurrido una eternidad desde aquel 8 de marzo de este año, que con las compañeras de la Red de Profesoras de la Facultad de Ciencias Jurídicas y Sociales de la UNLP, salimos a las calles abrazadas y con pañuelos verdes y violetas. Por momentos siento -en esta contradicción y falta de perspectiva en la que vivo-, que el panorama en torno a las conquistas de los feminismos ha empeorado. La cuarentena obligatoria coloca en una situación de doble vulnerabilidad a las mujeres y a les niñes causando "la otra pandemia". ¿Qué pasa con las mujeres 
y niñes que comparten la cuarentena con sus abusadores? La "pandemia del hambre" que conlleva a la angustia de un día a día en el que ya no hay comida en la mesa ¿Qué pasa con los que viven hacinados en viviendas precarias o los que ni siquiera tienen un techo? Hay días que me aflora un morbo incontrolable y paso horas mirando las noticias para ver cuántos fueron los infectados y muertos del día. Otros días, pienso que todo es una broma absurda, una pesadilla. Como en la metamorfosis de Kafka, me despierto como Gregorio Samsa convertida en una monstruosa insecta -esta vez, cibernética-. Me enfrento a un mundo nuevo intensamente tecnológico que me oprime y que me borra. Varias veces intenté concentrarme para cerrar una idea para este ensayo, tratando de mantener la calma en este realidad incierta donde la mayor preocupación es mantener la salud de nuestros familiares y amigos (muchos en las trincheras por pertenecer al sistema de salud y otres vulnerables por ser adultos mayores y con enfermedades preexistentes). El home working constante, las reuniones de zoom, el canal de YouTube, las cátedras virtuales, las aulas web y las mil plataformas a las que tenemos que acceder todos los días, me impiden encontrar ese punto firme de reflexión en un contexto donde caen todas mis convicciones. Una abogada y docente de Derecho debería poder interpretar la realidad o intentarlo al menos. Sin embargo, se me hace imposible proyectar más allá del día presente, cuando no se sabe a ciencia cierta cuándo finalizará esta pandemia. Imposible construir una conversación cultural en un entorno que no está apropiado de la identidad y que está invadido de pantallas, plataformas y aplicaciones virtuales. Me doy cuenta del privilegio que tengo de confinarme en la virtualidad y me avergüenzo...

\section{Bibliografía}

Alcaraz, Florencia (2017) ¿Una nueva ola del feminismo? En línea en: https://notasperiodismopopular.com.ar/2017/02/22/nuevaola-feminismo/.com 
Amorós, Celia (1990) "El feminismo: senda no transitada de la Ilustración" en Isegoría. Revista de Filosofía moral y política. $\mathrm{N}^{\mathrm{o}}$ 1. Madrid

Amorós, Celia (2005) La gran diferencia y sus pequeñas consecuencias para las luchas de las mujeres. Editorial Cátedra. Madrid. Aristóteles (1988) Política. Editorial Gredos. Barcelona

Bauger, Erika Silvina (2019) "Perspectiva de géneros y feminismos jurídicos en la enseñanza del derecho" en Derechos En Acción. $\mathrm{N}^{\circ}$ 11. En línea en: https://doi.org/10.24215/25251678e277

Benhabib, Seyla (2006) Las reivindicaciones de la cultura. Igualdad y diversidad en la era global. Editorial Katz. Buenos Aires

Bessis, Sophie (2002). Occidente y los otros. Editorial Alianza. Madrid

Bidaseca, Karina (2011) "Mujeres blancas buscando salvar a mujeres color café: desigualdad, colonialismo jurídico y feminismo postcolonial" en Andamios. $\mathrm{N}^{\circ}$ 17. CDMX. En línea en: http://www.scielo.org.mx/scielo.php?script=sci_arttext\&pi $\mathrm{d}=$ S1870-00632011000300004

Biswas, Andrea (2004). La tercera ola feminista: cuando la diversidad, las particularidades y las diferencias son lo que cuenta Editorial Universidad Autónoma Metropolitana. CDMX. En línea en: http://www.difusioncultural.uam.mx/revista/ sep2004/biswas.pdf

Boaventura De Sousa, Santos (1995) "Hacia una concepción multicultural de los derechos humanos", en Toward a new common sense, Law, science and politics in the paradigmatic transition. Editorial Routledge. Nueva York.

Bohman, James (1998) "The Coming of Age of Deliberative Democracy" en The Journal of Political Philosophy. $\mathrm{N}^{\circ} 4$. New York

Briones, Claudia (2005) Cartografías argentinas. Politicas indigenistas y formaciones provinciales de alteridad. Editorial Antropofagia. Buenos Aires.

Butler, Judith (1999) "Sujetos de sexo/género/deseo" en Gender trouble. Feminism and the Subversion of Identity. Editorial Paidós. Barcelona.

Carabajal, Mariana (2007) "La dirigente wichí que acusa a la Corte salteña por discriminación. En línea en: https://www.pagina12. com.ar/diario/sociedad/3-87477-2007-07-02.html 
Cobo, Rosa (2015) "El feminismo contra las políticas neoliberales". En línea en: https://www.eldiario.es/zonacritica/feminismopoliticas-neoliberales_6_375922427.html

Costa Wegsman, Malena (2011) "Críticas del Derecho y feminismos jurídicos" en II Jornadas del Centro Interdisciplinario de Investigaciones en Género. La Plata. En línea en: http://www. memoria.fahce.unlp.edu.ar/trab_eventos/ev.4893/ev.4893.pdf

Davis, Angela (1981) Mujeres, raza y clase. Editorial Akal. Madrid. Díaz Barriga, Ángel (2005) El docente y los programas escolares. Lo institucional y lo didáctico. Editorial Pomares S.A. Barcelona.

Elster, Jon (1988). Uvas amargas. Sobre la subversión de la racionalidad. Editorial Península. Barcelona.

Femenías María Luisa (1988) "Mujer y jerarquía natural en Aristóteles" en Encuentro Internacional de Filosofía y Feminismo. UNAM. En línea en: http://www.hiparquia.fahce.unlp.edu.ar/ numeros/voli/hiparquiav1a1

Femenías, María Luisa (2000) Sobre sujeto y género. Lecturas feministas desde Beauvoir a Butler. Editorial Catálogos. Buenos Aires.

Femenías, María Luisa y Vidiella, Graciela (2017) "Multiculturalismo y género. Aportes de la democracia deliberativa” en Revista Europea de Derechos Fundamentales.

Foucault, Michel (1966) Las palabras y las cosas. Siglo XXI Editores. CDMX

Foucault, Michel (1981) Vigilar y castigar: nacimiento de la prisión. Siglo XXI Editores. CDMX

Foucault, Michel (1982) Historia de la sexualidad 1. La voluntad del saber. Siglo XXI Editores. CDMX

Freedman, Jane (2004) Feminismo ¿unidad o conflicto? Editores Narcea. Barcelona

Giddens, Anthony (1999) "Riesgo y responsabilidad" en The Modern Law Review. № 62. New York.

González Vázquez, Araceli (2013) "Los conceptos de patriarcado y androcentrismo en el estudio sociológico y antropológico de las sociedades de mayoría musulmana" en Paper $\mathrm{N}^{0}$ 3. Collège de France/EHESS. Laboratoire d'Anthropologie Sociale.

Guerra Palmero, María (2011). "La mujer-filósofo o la más "antinatural" de las criaturas. En torno a Simone de Beauvoir y a su 
obra El segundo sexo" en Revista Valenciana. Estudios de Filosofía y Letras. $\mathrm{N}^{\circ}$ 7: enero-junio 2011, pp. 131-146. En línea en: http://www.revistavalenciana.ugto.mx/index.php/valenciana/ article/view/229

Guha, Rahanit (2002) Las voces de la historia y otros estudios subalternos. Editorial Crítica. Barcelona

Hernández Castillo, Aída (2003) "Re-pensar el multiculturalismo desde el género. Las luchas por el reconocimiento cultural y los feminismos de la diversidad". En Revista de Estudios de Género. $\mathrm{N}^{\mathrm{o}} 18$ Universidad de Guadalajara. En línea en: http:// www.redalyc.org/articulo.oa?id=88401803

Lerussi, Carla y Costa, Malena (2018). "Los feminismos jurídicos en Argentina. Notas para pensar un campo emergente a partir de la década de 1990" en Rev. Estud. Fem. N ${ }^{\circ} 1$. En línea en: http://dx.doi.org/10.1590/1806-9584.2018v26n141972

Mastrodoménico, Isabel (2018). Las feministas queremos. 12 respuestas claras a la pregunta: "pero... ¿qué más quieren las feministas?". Editorial Lo que no existe. Barcelona

Moller Okin, Susan. (1989). Women in Western Political Thought. En línea en: https://es.scribd.com/book/232956423/Womenin-Western-Political-Thought

Moller Okin, Susan (1999). “Es el multiculturalismo malo para las mujeres?", en Is Multiculturalism Bad for Women? Editorial Princenton University Press. Princeton

Olsen, Frances (1990). "El sexo del derecho" en Identidad femenina y discurso jurídico. Editorial Biblos. Buenos Aires.

Palmer, John (s/f) "La comunidad está de duelo por la muerte simbólica de Fabián”. En: http://www.delorigen. com.ar/john.htm

Palmer, John (2005). La buena voluntad wichi. Una espiritualidad indígena. En línea en: https://vimeo.com/128680532

Piccone, María Verónica (2018). "Filosofía, política, justicia y género. Aproximación al pensamiento de Platón y Rousseau en torno a las mujeres" en Redea. Derechos en acción | Año 3 $\mathrm{N}^{\circ}$ 6. La Plata.

Platón (1988) República. Editorial Gredos. Barcelona

Quijano, Anibal (2000), "Colonialidad del poder, eurocentrismo y América Latina", en La colonialidad del saber: eurocentrismo 
y ciencias sociales. Perspectivas latinoamericanas. Editorial CLACSO Buenos Aires-Caracas.

Ramírez, Silvina y Carrasco, Morita (2012). Cuando se juzga a un indigena se deben respetar ciertas diferencias para honrar el principio de igualdad. En línea en https://www.palermo.edu/ derecho/noticias/indigenas.html

Salih, Sara (2002). Judith Butler. Routledge. En línea en: https:// www.worldcat.org/title/judith-butler/oclc/994596758?referer= di\&ht=edition

Santa Cruz, María Isabel (1999) Justicia y Género en Platón. En línea en: http://www.memoria.fahce.unlp.edu.ar/art_revistas/ pr.5480/pr.5480.pdf

Segato, Rita Laura (2004). "Antropología y Derechos Humanos: alteridad y ética en el movimiento de los derechos universales". En Série Antropología $\mathrm{N}^{\circ} 356$. San Pablo

Tarducci, Mónica (2013). "Abusos, mentiras y videos. A propósito de la niña wichi" en Boletín de Antropología y Educación. Año 4 - No 05. Buenos Aires

Viveros Vigoya, Mara (2016). "La interseccionalidad: una aproximación situada a la dominación" en Debate Feminista. $\mathrm{N}^{\circ} 52$. 